\title{
NOTAS DE JURISPRUDENCIA
}

\section{Tribunal Constitucional (*)}

\section{DERECHOS Y LIBERTADES}

\section{A. Derechos fundamentales y libertades públicas.}

\section{Sentencia 13/2011 de 28 de febrero (BOE de 29 de marzo). Po- nente: Rodríguez Arribas (Recurso de amparo).}

Preceptos constitucionales: 9.3, 14, 24.1, 117.3

otros:

Objeto: Auto de 18 de diciembre de 2006, que desestimó el incidente de nulidad de actuaciones promovido contra la Sentencia de 13 de julio de 2006 de la Sección Primera de la Sala de lo Contencioso-Administrativo del Tribunal Superior de Justicia de la Comunidad Valenciana, dictada en el recurso contencioso-administrativo núm. 2449-2004 contra la resolución del Tribunal Económico-Administrativo Regional de Valencia de fecha 13 de octubre de 2004.

Materias: Tutela judicial efectiva; derecho a la igualdad en la aplicación judicial de la ley. Seguridad jurídica.

Precisará el TC el objeto de la controversia: el recurso de amparo, aunque formalmente se interpone contra el Auto, de fecha 18 de diciembre de 2006, que desestimó el incidente de nulidad de actuaciones promovido por el recurrente, se dirige en lo sustancial contra la Sentencia de 13 de julio de 2006 de la Sección Primera de la Sala de lo Contencioso-Administrativo del Tribunal Superior de Justicia de la Comunidad Valenciana, dictada en el recurso contencioso-administrativo núm. 2449-2004 contra la resolución del Tribunal Económico-Administrativo Regional de Valencia de fecha 13 de octubre de 2004; considerará el TC que el objeto no es sino la atribución de la

\footnotetext{
(*) Subsección preparada por FRANCISCO ESCRIBANO. Catedrático de Derecho Financiero. Universidad de Sevilla.
} 
parte de vulneración del principio de cosa juzgada y una carencia de motivación lesivas del derecho a la tutela judicial efectiva (art. 24.1 CE) y la lesión del derecho a la igualdad en la aplicación judicial de la ley (art. $14 \mathrm{CE}$ ), fundándose dichas lesiones en la existencia de una Sentencia previa a la impugnada, dictada por el mismo órgano judicial, en la que se resuelve un recurso sustancialmente idéntico presentado por el hermano del recurrente. Entrará a conocer el TC sobre cuestiones de índole procesal por cuanto pudieran determinar la inadmisibilidad de la demanda de amparo; analizará el TG si el recurso presentado incurre en la causa de inadmisión prevista en el art. 44.2 de la Ley Orgánica del Tribunal Constitucional (LOTC), al haberse formulado una vez transcurrido el plazo legal de veinte días desde la notificación de la resolución judicial impugnada; recordará el TC la existencia del art. 44.2 LOTC, en cuya virtud se establece la exigencia de que el recurso se interpusiera dentro del plazo de veinte días a partir de la notificación de la resolución judicial que pone fin a la vía jurisdiccional, en la redacción anterior a la Ley Orgánica 6/2007, de 29 de mayo; considera el TC que este plazo es de caducidad, improrrogable y no susceptible de suspensión y, por consiguiente, de inexorable cumplimiento, que no consiente una prolongación artificial ni puede quedar al arbitrio de las partes mediante la utilización de recursos manifiestamente improcedentes; traerá en su apoyo el TC su propia doctrina consolidada en el sentido de que la armonización de las exigencias del principio de seguridad jurídica (art. 9.3 CE) y el derecho a la tutela judicial efectiva (art. 24.1 CE) conducen a una aplicación restrictiva del concepto de recurso manifiestamente improcedente, limitándolo a los casos en que tal improcedencia derive de manera terminante, clara e inequívoca del propio texto legal, sin dudas que hayan de resolverse con criterios interpretativos de alguna dificultad, o, en otras palabras, cuando dicha improcedencia sea evidente, es decir, constatable prima facie, sin intervención de dudas interpretativas que sea necesario despejar por medio de criterios hermenéuticos no absolutamente indiscutibles; precisará, además, el TC que el cómputo del plazo de veinte días establecido en el art. 44.2 LOTC, en la redacción anterior, para la interposición del recurso de amparo ha de ponerse necesariamente en conexión con lo dispuesto en la letra a) del primer apartado del mismo precepto, que exige el agotamiento de todos los recursos utilizables dentro de la vía judicial, al tiempo que reconocerá que ello sitúa al justiciable ante una delicada disyuntiva sobre el modo en que debe dar adecuada satisfacción al referido requisito procesal que franquea el acceso al amparo, puesto que una ac- 
titud medrosa o, por el contrario, arriesgada en el cálculo de la estrategia procesal pertinente puede conducir a un incumplimiento por defecto o por exceso que dé lugar a la producción del referido óbice procesal, haciendo que la demanda de amparo resulte extemporánea (SSTC 217/2002, FJ 2; 23/2005, FJ 3; 114/2005, FJ 2; y 127/2005, FJ 2, por todas); en atención a esta circunstancia ya tiene declarado el TC que los recursos, aun cuando sean improcedentes, suspenden el plazo de veinte días para recurrir en amparo cuando de las circunstancias del caso se colija que el recurrente obra en la creencia de que hace lo correcto y, por consiguiente, actúa sin ánimo dilatorio, como puede suceder si es la propia resolución judicial recurrida la que induzca, mediante su expresa mención, a la interposición del recurso (por todas, STC 23/2005, FJ 2). De acuerdo con su doctrina, el TG considera que en esta ocasión el incidente de nulidad de actuaciones no puede ser calificado de manifiestamente improcedente a efectos de la interrupción del plazo para la interposición del recurso de amparo; del examen del escrito de interposición se desprende que el recurrente instó la nulidad de actuaciones por considerar que la ausencia de motivación sobre el cambio de criterio jurisprudencial constituía un defecto de forma causante de indefensión; y ello con independencia de que el órgano judicial en su Auto desestimatorio no compartiera tal interpretación y aplicación al caso de la legalidad procesal; considerará el TC que lo cierto es que, a los efectos que aquí interesan, no puede calificarse prima facie de inviable ni por completo ajena al tenor del art. 241 LOPJ, de tal modo que no cabe apreciar en el recurrente un interés dilatorio que permita apreciar un vicio de extemporaneidad; el segundo óbice procesal que dilucidará el TC gira en torno a la causa de inadmisibilidad, aducida por la Abogacía del Estado, de no haberse agotado adecuadamente la vía judicial previa conforme a lo exigido por el art. 44.1 a) LOTC, al considerar que previamente a la denuncia de su derecho a la igualdad en la aplicación de la Ley el recurrente hubiera debido instar la extensión a su caso de la Sentencia anterior, conforme al art. 110 Ley reguladora de la jurisdicción contencioso- administrativa; el TG rechazará de plano tal objeción al entender que de la simple lectura del precepto indicado se desprende que la extensión de efectos de sentencias firmes que hubieran reconocido una situación jurídica individualizada en materia tributaria no se configura en la Ley reguladora de la jurisdicción contencioso-administrativa como un remedio procesal frente a Sentencias lesivas de la igualdad sino como un procedimiento preventivo y simplificador del procedimiento judicial, que no puede configurarse como una obligación del ciudadano, ni mucho 
menos entenderse su omisión como una renuncia al derecho a la igualdad en la aplicación judicial de la ley; añadirá el TC, además, que la ausencia de la identidad subjetiva requerida para la concurrencia de la cosa juzgada material impide su pronunciamiento al respecto (como recientemente ha sido recordado en SSTC 208/2009, FJ 6 , y $71 / 2010$, FJ. 3). En relación con el fondo del asunto -lesión del principio de igualdad en la aplicación judicial de la ley- considera el TC necesario recordar la doctrina constitucional consolidada, resumida en la reciente STC 31/2008, FJ 2, en cuanto a los requisitos que han de concurrir para poder apreciar la lesión del referido principio: (a) La acreditación de un tertium comparationis, puesto que el juicio de igualdad sólo puede realizarse sobre la comparación entre la Sentencia impugnada y las precedentes resoluciones del mismo órgano judicial dictadas en casos sustancialmente iguales pero resueltos de forma contradictoria; (b) la identidad de órgano judicial, entendiendo por tal, no sólo la identidad de la Sala, sino también la de la Sección, al considerarse cada una de éstas como órgano jurisdiccional con entidad diferenciada suficiente para desvirtuar una supuesta desigualdad en la aplicación de la ley; y añadirá el TC: esta exigencia permite valorar si la divergencia de criterio expresada por el juzgador es fruto de la libertad de apreciación del órgano jurisdiccional en el ejercicio de su función juzgadora (art. 117.3 CE) y consecuencia de una diferente apreciación jurídica de los supuestos sometidos a su decisión, o, por el contrario, un cambio de valoración del caso, carente de fundamentación suficiente y razonable; (c) la existencia de alteridad en los supuestos contrastados, es decir, de la referencia a otro exigible en todo alegato de discriminación en aplicación de la ley, excluyente de la comparación consigo mismo; (d) finalmente la ausencia de toda motivación que justifique en términos generalizables el cambio de criterio, bien lo sea para separarse de una línea doctrinal previa y consolidada, bien lo sea con quiebra de un antecedente inmediato en el tiempo y exactamente igual desde la perspectiva jurídica con la que se enjuició; explicitará el TC, además, la razón de esta última exigencia: estriba en que el derecho a la igualdad en la aplicación de la ley, en conexión con el principio de interdicción de la arbitrariedad (art. 9.3 $\mathrm{CE}$ ), obliga a que un mismo órgano jurisdiccional no pueda cambiar caprichosamente el sentido de sus decisiones adoptadas con anterioridad en casos sustancialmente iguales sin una argumentación razonada de dicha separación que justifique que la solución dada al caso responde a una interpretación abstracta y general de la norma aplicable y no a una respuesta ad personam, singularizada; ello significará 
negativamente que no podrá apreciarse la lesión de este derecho fundamental cuando el cambio de criterio responda a una vocación de generalidad, ya sea porque en la resolución se explicitan las razones que lo motivan o porque así se deduzca de otros elementos de juicio externos, como pueden ser significativamente posteriores pronunciamientos coincidentes con la línea abierta en la Sentencia impugnada, que permitan apreciar dicho cambio como solución genérica aplicable en casos futuros y no como fruto de un mero voluntarismo selectivo frente a casos anteriores resueltos de modo diverso. La aplicación de esta asentada doctrina lleva al TC al otorgamiento del amparo solicitado, estimando que de la lectura de la Sentencia recurrida y la aportada como contraste se desprende sin ninguna duda que, pese a su resultado divergente, ambas versan sobre supuestos idénticos. Los dos recursos contencioso-administrativos interpuestos se dirigían contra dos resoluciones idénticas, de 13 de octubre de 2004, del Tribunal Económico-Administrativo Regional de Valencia que venían a resolver las reclamaciones económico-administrativas, interpuestas por los recurrentes, contra la comprobación de valores instada por la Administración tributaria sobre unos derechos de explotación minera que ambos habían recibido en donación. El objeto de ambos recursos contencioso- administrativo era pues idéntico, coincidiendo también la motivación de ambos. En la Sentencia impugnada en amparo, dictada con posterioridad, no se alude en ningún momento a la anterior ni, por ello mismo, se justifica siquiera mínimamente el cambio de criterio jurisprudencial. Las dos resoluciones judiciales fueron dictadas por la Sección Primera de la Sala de lo Contencioso-Administrativo del Tribunal Superior de Justicia de la Comunidad Valenciana. La alteridad, por su parte, viene implícita en el hecho de que se trata de dos recurrentes distintos, siendo un requisito personal que no alude al objeto del proceso sino a la persona que sufre el trato discriminatorio frente a la otra a la que se refiera la Sentencia de contraste.

\section{Sentencia 23/2011, de 14 de marzo (BOE de 11 de abril). Ponen- te: Delgado Barrio (Recurso de amparo).}

Preceptos constitucionales: $9.3 ; 24.1$

otros:

Objeto: Sentencia de la Sala de lo Contencioso-Administrativo del Tribunal Superior de Justicia de Illes Balears de fecha 20 de febrero de 2007, por la que se 
desestima el recurso contencioso-administrativo interpuesto frente a la resolución del Tribunal Económico-Administrativo Regional en Illes Balears de 29 de octubre de 2004, que inadmite el recurso de anulación interpuesto contra una decisión anterior del mismo órgano de 29 de julio de 2004, relativa a liquidación del impuesto sobre transmisiones patrimoniales.

Materias: Tutela judicial efectiva; seguridad jurídica.

Comenzará el TC tratando de centrar la cuestión que se somete a su juicio, según su criterio consiste en dilucidar si la Sentencia de la Sala de lo Contencioso-Administrativo del Tribunal Superior de Justicia de Illes Balears de 20 de febrero de 2007, dictada en el recurso contencioso-administrativo núm. 77-2005, ha vulnerado el derecho a la tutela judicial efectiva del demandante de amparo por haberse negado el órgano judicial a responder a las cuestiones de fondo planteadas en su demanda contencioso-administrativa respecto de la resolución del Tribunal Económico-Administrativo Regional en Illes Balears de 29 de julio de 2004, basándose en que éstas quedaban fuera de su ámbito de decisión, por resultar éste restringido a determinar si el recurso de anulación del art. 239.6 de la Ley General Tributaria (LGT) interpuesto por el recurrente, había sido correctamente declarado inadmisible por el Tribunal Económico-Administrativo Regional en Illes Balears en su resolución de 29 de octubre de 2004. Se trata de determinar si mediante la Sentencia impugnada se vulnera el derecho a la tutela judicial efectiva en su vertiente de acceso a la jurisdicción, por haber limitado injustificadamente el derecho a que la pretensión fuera examinada por el órgano judicial y a obtener una respuesta motivada sobre la misma, solicitud del demandante, ahora en amparo a la que se une el Ministerio Fiscal; oponiéndose, por el contrario, el Abogado del Estado y el de la Comunidad Autónoma, entendiendo que la Sentencia impugnada no incurre en incongruencia omisiva ni vulnera el derecho de acceso a la jurisdicción, pues el órgano judicial se ha limitado a constatar la imposibilidad legal de entrar a analizar cuestiones que quedan fuera del ámbito del recurso. Centrada así la cuestión, el TC afronta una cuestión previa planteada por el Abogado del Estado: la de que el recurso de amparo debería considerarse inadmisible por extemporáneo, dado que fue iniciado cuando ya había transcurrido el plazo de veinte días del art. 44.2 de la Ley Orgánica del Tribunal Constitucional (LOTC), en la redacción vigente en el momento de su interposición. La extemporaneidad se habría producido porque el recurrente in- 
terpuso un incidente de nulidad de actuaciones que era un remedio manifiestamente improcedente para reparar la lesión del derecho a acceder a la jurisdicción contencioso-administrativa y a obtener un pronunciamiento de fondo, por no tratarse de un defecto de forma ni de una incongruencia en ninguna de sus modalidades. El TC considera que la extemporaneidad alegada debe ser rechazada: El recurrente planteó el incidente de nulidad de actuaciones al considerar que la Sentencia incurría en incongruencia omisiva, y así lo entiende también el Fiscal en el informe emitidos en estos autos al no haberse pronunciado sobre las pretensiones que debidamente planteó en la demanda; al fundamentar este incidente en uno de los motivos que, de acuerdo con la redacción entonces vigente del art. 241 de la Ley Orgánica del Poder Judicial (LOPJ), justificaban su formulación y pretender a través de esta vía que el órgano judicial entrara a resolver cuestiones que quedaron imprejuzgadas por la Sentencia cuya nulidad solicitaba no puede considerarse que el recurso incurra en la manifiesta improcedencia que le atribuye el Abogado del Estado. Traerá en su apoyo el TC su doctrina (por toda STC 47/2006, FJ 2), la armonización de las exigencias del principio de seguridad jurídica (art. 9.3 CE) y el derecho a la tutela judicial efectiva (art. 24.1 CE) conducen a una aplicación restrictiva del concepto de recurso manifiestamente improcedente, limitándolo a los casos en que tal improcedencia derive de manera terminante, clara e inequívoca del propio texto legal, sin dudas que hayan de resolverse con criterios interpretativos de alguna dificultad; así como la que se resume en la STC 76/2009, FJ 2 en cuya virtud el respeto debido al derecho de la parte a utilizar cuantos recursos considere útiles para la defensa de sus intereses impide exigirle que se abstenga de emplear aquellos cuya improcedencia sea razonablemente dudosa y, en consecuencia, que asuma el riesgo de incurrir en una falta de agotamiento de la vía judicial previa. Es criterio del Tc que en el caso que ahora se examina la improcedencia del recurso no se deriva de manera terminante, clara e inequívoca del propio texto legal, ya que, como se ha indicado, el incidente se suscitó aduciendo uno de los motivos previstos en la Ley -incongruencia- y lo solicitado -que se dé respuesta a cuestiones que quedaron imprejuzgadas- no resulta a todas luces incompatible con la función institucional del correspondiente remedio procesal, de acuerdo con su regulación legal y con la jurisprudencia del Tribunal Supremo (ATC 198/2010, FJ 4); a tenor de esta doctrina estimará el TC que no puede entenderse que, a efectos de agotar la vía judicial previa al recurso de amparo, el incidente de nulidad de actuaciones planteado haya de considerarse manifiestamente improcedente. Estimará el TC que la Sentencia impugnada contiene expresamente una decisión de 
no pronunciamiento sobre el fondo y es doctrina reiterada de éste (por ejemplo en la STC 25/2010, FJ 3, que el control constitucional de las decisiones de inadmisión o de no pronunciamiento sobre el fondo ha de verificarse de forma especialmente intensa, dada la vigencia aqui del principio pro actione, principio de obligada observancia por los Jueces y Tribunales que impide que determinadas interpretaciones y aplicaciones de los requisitos establecidos legalmente para acceder al proceso eliminen u obstaculicen injustificadamente el derecho a que un órgano judicial conozca y resuelva en Derecho sobre la pretensión a él sometida; ciertamente, continuará recordando el TC el principio pro actione no debe entenderse como la forzosa selección de la interpretación más favorable a la admisión o a la resolución del problema de fondo de entre todas las posibles de las normas que la regulan, ya que esta exigencia llevaría al Tribunal Constitucional a entrar en cuestiones de legalidad procesal que corresponden a los Tribunales ordinarios (SSTC 207/1998, de 26 de octubre, F7 2; 78/1999, de 26 de abril, Ff 3; 64/2005, de 14 de marzo, Ff 2, por todas), y es que lo que en realidad implica este principio es la interdicción de aquellas decisiones de inadmisión -o de no pronunciamiento- que por su rigorismo, por su formalismo excesivo o por cualquier otra razón revelen una clara desproporción entre los fines que aquellas causas de inadmisión -o no pronunciamiento sobre el fondo- preservan y los intereses que sacrifican (entre otras muchas, SSTC 160/2001, de 5 de julio, Ff 3; 27/2003, de 10 de febrero, Ff 4; 177/2003, de 13 de octubre, FF 3; 3/2004, 14 de enero, FF 3; 79/2005, de 4 de abril, Ff 2; 133/2005, de 23 de mayo, FJ 2). (STC 25/2010, de 27 de abril, FJ 3). Se adentrará el TC en el objeto central del recurrente, recordando la finalidad del art. 239.6 y advirtiendo que el Tribunal Regional, decidiendo el recurso de anulación en su resolución de 29 de octubre de 2004, estudia extensamente el motivo alegado -incongruencia completa y manifiesta de la resolución-, que constituía precisamente el fondo del recurso, pero lo declara inadmisible, resolución ésta contra la que se interpuso recurso contencioso-administrativo que terminó con la Sentencia aquí impugnada en amparo. Apreciará el TG que esta Sentencia considera que sólo forma parte del ámbito de su conocimiento la resolución del Tribunal Económico-administrativo Regional en Illes Balears de 29 de octubre de 2004, que es la que decide el recurso de anulación interpuesto, por entender que debía limitarse a analizar si concurría el motivo de anulación invocado, sin que procediera examinar si la resolución impugnada en anulación incurría en las otras infracciones del ordenamiento jurídico alegadas. Destacará ahora el TG que que las cuestiones planteadas en estos autos tienen como punto de partida la delimitación del contenido objetivo del citado recurso contencioso, pues la pregunta a contestar es la de si la 
interposición de un recurso de anulación previo, facultativo y con motivos tasados -concretados por razones de gravedad, por un lado, y de una cierta sencillez que facilita su apreciación, por otro- traslada al ulterior recurso, en este caso jurisdiccional, la limitación de la cognitio que es propia del señalado cauce previo. Para decidir sobre esta cuestión analizará el TC la finalidad y el sentido del mencionado recurso de anulación: El recurso de anulación establecido en el art. 239.6 LGT, de motivos tasados, es un remedio que, en su espiritu y finalidad -art. 3.1, Título Preliminar del Código civil- aspira a hacer innecesario el planteamiento de un ulterior recurso, éste de plena cognitio; carecería de sentido que un remedio, basado en motivos tasados y que tiene como finalidad evitar un recurso posterior, en caso de quedar frustrada tal finalidad, provocara para éste, que no ha podido evitarse, la misma limitación de la cognitio que es propia del remedio; este no sólo habría fracasado sino que, además, habría cercenado el contenido natural del recurso posterior que no había conseguido hacer innecesario. Rematará su argumentación el TC de este modo: Si alguna duda hubiera respecto del sentido del art. 239.6 LGT, quedaría aclarada por el art. 60 del Reglamento General en materia de revisión en vía administrativa, aprobado por Real Decreto 520/2005, de 13 de mayo (RGRVA), en sus apartados 2 -el plazo para la alzada sólo empieza a correr con la resolución expresa o presunta del recurso de anulación- y 4: la resolución que se dicte como consecuencia del recurso de anulación sólo podrá ser impugnada en el mismo recurso que pudiera proceder contra el acuerdo o la resolución de la reclamación, lo que implica que el recurso de anulación no sólo no influye, recortándolo, en el ámbito objetivo de la congnitio del ulterior recurso, sino que, al contrario, es la resolución del recurso de anulación la que pierde su sustantividad, pues se engloba, para su impugnación, dentro del contenido más amplio de ese recurso posterior. A partir de esta interpretación funcional y finalista del recurso de anulación contemplado en el art. 239.6 LGT y 60 RGRVA afrontará el TG el tramo final de su argumentación: La Sentencia aquí impugnada no lo ha entendido así y, dado que el demandante había interpuesto el recurso de anulación que le había sido ofrecido, no ha entrado en el conocimiento de las cuestiones de fondo planteadas y que versaban, en lo fundamental, sobre la conformidad o disconformidad a Derecho de una liquidación por el impuesto sobre transmisiones patrimoniales: se limita a examinar si concurría el motivo de nulidad que se atribuyó a la resolución de 29 de julio de 2004, declarando que las indicadas cuestiones de fondo quedaban extramuros del limitado espacio de cognición propio del recurso 77- 
2005; para el TC, con ello la citada sentencia traslada la limitación de la cognitio del recurso de anulación al posterior recurso contencioso-administrativo que aquél no consiguió evitar; considerará el TC que tal solución es fruto de una interpretación del art. 239.6 LGT claramente desproporcionada, habida cuenta de que la finalidad perseguida por el recurso de anulación, que es la de evitar la interposición de un ulterior recurso, para nada exige que éste quede sometido a la misma limitación de la cognitio que afecta a aquél, con lo que ha venido a crearse una causa de no pronunciamiento sobre el fondo del asunto desprovista de base legal. En atención a estas consideraciones el TC concluye que el órgano judicial, al limitar su enjuiciamiento a la resolución por la que se inadmitió el recurso de anulación y no llegar a pronunciamiento alguno sobre el contenido de los motivos de fondo suscitados en el recurso contencioso-administrativo, ha dejado de dar respuesta a todas las cuestiones controvertidas en el proceso, como establece el art. 67.1 de la Ley reguladora de la jurisdicción contencioso-administrativa, sin que exista una causa legal que fundamente su decisión de no pronunciamiento, vulnerando de este modo el derecho del recurrente a la tutela judicial efectiva en su vertiente de derecho de acceso a la jurisdicción. Se otorga el amparo solicitado reconociéndose el derecho a la tutela judicial efectiva en su vertiente de acceso a la jurisdicción (art. 24.1 CE); se declara la nulidad de Sentencia de 20 de febrero de 2007 dictada por la Sala de lo Contencioso-Administrativo del Tribunal Superior de Justicia de Illes Balears y se ordena retrotraer las actuaciones al momento anterior al del pronunciamiento de dicha Sentencia para que se dicte una nueva resolución respetuosa con el derecho fundamental reconocido.

\section{Sentencia 39/2011, de 31 de marzo (BOE de 28 de abril). Ponen- te: Delgado Barrio (Guestión de inconstitucionalidad).}

Preceptos constitucionales: 24.2.
otros:

Objeto: Art. 61.2. párrafo segundo, de la Ley 230/1963, de 28 de diciembre, General Tributaria (LGT), en la redacción derivada de la Ley 18/1991, de 6 de junio, por la posible vulneración del art. 24.2 CE

Materias: Sanciones: régimen jurídico; garantías procesales. 
En la STC 291/2000, el Pleno de este Tribunal otorgó el amparo solicitado frente a la Sentencia de la Sala de lo Contencioso-Administrativo del Tribunal Superior de Justicia de Galicia de 6 de junio de 1994, recaída en el recurso contencioso-administrativo núm. 037492-1994 interpuesto contra la Resolución de la Delegación de Vigo de la Agencia Estatal de la Administración Tributaria notificada en el "Boletín Oficial del Estado" el 8 de octubre de 1993 mediante la que, en aplicación de lo previsto en el segundo párrafo del art. 61.2 de la LGT, en la redacción dada por la Ley 18/1991, se impuso al recurrente un recargo del 100\% sobre la deuda tributaria. El art. 61.2 LGT, hoy derogado, rezaba literalmente así: 2. Los ingresos correspondientes a declaraciones, liquidaciones o autoliquidaciones realizadas fuera de plazo sin requerimiento previo, sufrirán un recargo único del 50\%, con exclusión del interés de demora y de las sanciones que pudieran ser exigibles. No obstante, el recargo será del 10\% si el ingreso se efectúa dentro de los tres meses siguientes al término del plazo voluntario de presentación e ingreso. Cuando los obligados tributarios no efectúen el ingreso al tiempo de la presentación de las declaraciones, liquidaciones o autoliquidaciones extemporáneas, sin solicitar expresamente el aplazamiento o el fraccionamiento del pago, se les exigirá en vía de apremio con un recargo único del 100 por 100" La STC 291/2000 estimó que, "al haberse impuesto al recurrente un recargo de naturaleza sancionadora sin procedimiento contradictorio alguno, la Administración ha infringido el art. 24.2 CE al no respetar el derecho fundamental del demandante de amparo a no ser sancionado si no es a través del correspondiente procedimiento en el que, con las modulaciones que procedan, se respeten las garantías que se deducen de este precepto constitucional (FJ 12). Considerará el TG que, al encontrarnos ante un supuesto en el que el precepto legal que ha sido objeto de aplicación al presente caso (art. 61.2, párrafo segundo, LGT en la redacción dada por la Ley 18/1991) pudiera ser inconstitucional por vulnerar el art. $24.2 \mathrm{CE}$, el Pleno... plantea la cuestión de inconstitucionalidad, ya que a pesar de que dicho precepto se halla hoy derogado por la Ley 25/1995, de 20 de julio, de modificación parcial de la Ley general tributaria, no cabe descartar su aplicación a situaciones jurídicas pendientes (SSTC 140/1986, de 11 de noviembre, FF 9; y 46/1999, de 22 de marzo, Ff3) (FJ 14). El Abogado del Estado, a la vista de la doctrina sentada en las SSTC 291/2000 y 276/2000, de 16 de noviembre, no pone en duda el carácter sancionador del recargo del 100 por 100 previsto en el art. 61.2, párrafo segundo, LGT. Por su parte, el Fiscal General del Estado interesa que se declare inconstitucional el art. 61.2, párrafo segundo, LGT, en el inciso que impone un recargo único del 100 por 100 que se exigirá en vía de apremio, dado que, a tenor de la doctrina sentada en las SSTC 291/2000 y 276/2000, aunque no lesiona el prin- 
cipio de legalidad sancionadora, dicho recargo constituye una sanción que se impone sin aplicar las garantías propias del ámbito administrativo sancionador y con vulneración, por tanto, del art. 24.2 CE. Entrará el TC en el fondo de la cuestión planteada recordando que la misma se suscita por la posible contradicción con el art. 24.2 CE del párrafo segundo de art. 61.2 LGT, en la redacción que se deriva de la Ley 18/1991; partiendo de la premisa de que, como ha señalado el TC en numerosas ocasiones, las garantías materiales y procesales recogidas en los arts. 24 y 25 CE sólo resultan aplicables a actos que responden al ejercicio del ius puniendi del Estado (SSTC 73/1982, FJ 3; 69/1983, FJ 4; 96/1988, FJ 3; 239/1988, FJ 2; 164/1995, FJ 4; 276/2000, FJ 3; 291/2000, FJ 8 y 121/2010, FJ 7), en la STC 291/2000 ya se interrogó, en primer lugar, acerca de la naturaleza del recargo del $100 \%$ establecido en el precepto ahora cuestionado y, con fundamento en la doctrina sentada en relación con el recargo del 50\% en la STC 276/2000, se llegó a la conclusión de que el recargo previsto en el párrafo segundo del art. 61.2 LGT tenía naturaleza sancionadora en la medida en que poseía la finalidad represiva, retributiva o de castigo que ha hemos venido destacando el TC como propia de las sanciones (entre otras, SSTC 239/1988, FJ 2; 164/1995, FJ 4; 276/2000, FJ 3; y 121/2010, FJ 7). En la STC 291/2000, FJ 9, ya se argumentó por el TC que para comprobar si el recargo establecido en el art. 61.2, párrafo segundo, LGT posee o no carácter sancionador es preciso atender a la función que dicho recargo tiene encomendada dentro del sistema tributario o, dicho de manera más precisa, determinar si dicho recargo tiene una función represiva -en cuyo caso, tratándose de una medida restrictiva de derechos que se impone como consecuencia de una infracción de la Ley, sólo podría justificarse, constitucionalmente, como sanción-, o si, por el contrario, a través del mismo se persiguen otras finalidades justificativas de las que se encuentre ausente la idea de castigo y que permitan, por lo tanto, aplicarlo sin necesidad de observar las garantías constitucionales que rigen la imposición de las sanciones" (STC 276/2000, FJ 4). $\mathrm{Y}$, tras indagar sobre las funciones que cumple el recargo del 100 por 100 que establece el párrafo segundo del art. 61.2 LGT, se resolvió por el TC que dicha medida tiene carácter sancionador. En efecto, al igual que en el recargo del 50 por 100 examinado en la STC 276/2000, en el que ahora enjuiciado cabe reconocer, ante todo, una medida que se concreta en la imposición de un mal o gravamen como consecuencia de la comisión por parte de su destinatario de una conducta ilícita que, además y en lo que ahora importa, resulta subsumible en la infracción administrativa tipificada entonces en el art. 
79 a) LGT -consistente, en la redacción entonces vigente, en dejar de ingresar, dentro de los plazos reglamentariamente señalados, la totalidad o parte de la deuda tributaria, de los pagos a cuenta o fraccionados, así como de las cantidades retenidas o que se hubieran debido retener-, y que constituye una forma de disuadir a los contribuyentes de que presenten las declaraciones liquidaciones o autoliquidaciones fuera de plazo; función que, aun cuando ciertamente no es determinante de la naturaleza sancionadora de un acto (por todas STC 276/2000, FJ 4), si que, en determinadas circunstancias, puede constituir un indicio de su carácter sancionador. De ahi que para poder apreciar si este recargo tenía este carácter tuvimos que comprobar que esta medida restrictiva no cumplía otras funciones que pusieran de manifiesto que estos tributos no tienen carácter represivo (STC 291/2000, FJ 9); en esta Sentencia ya consideró el TC aplicable al recargo del $100 \%$ la conclusión alcanzada a este respecto, a propósito del recargo del 50\%, en la STC 276/2000, en la que "[e]sta indagación nos llevó a descartar que estos recargos fueran un medio para constreñir el cumplimiento de una obligación (su función no es la de asegurar la ejecución de un acto administrativo, como ocurre con las multas coercitivas: STC 239/1988, F7 2). Tampoco consideramos que constituyeran una forma coactiva de asegurar la legalidad conculcada (SSTC 181/1990, de 15 de noviembre, Ff 4; 119/1993, de 19 de abril, F7 3). Si asi fuera la norma que prevé este recargo se limitaría a ordenar el pago de la deuda tributaria debida y a aplicar las medidas de neutralización financiera precisas para compensar a la Administración del coste que le supone dejar de disponer a tiempo de las cantidades dinerarias que le son legalmente debidas, lo que no ocurre en el caso del recargo del 50 por 100, ya que el pago de la cantidad de dinero en que el recargo consiste supera ampliamente la establecida en la Ley como intereses de demora. $Y$ por último descartamos que estos recargos tuvieran naturaleza tributaria, pues el plus de la deuda tributaria inicialmente prevista en las normas reguladoras de los impuestos que implica el recargo no tiene como fin la exigencia de un tributo -no existe un nuevo hecho imponible revelador de una nueva capacidad económica-, sino el pago de una cantidad adicional por haber incumplido el deber de ingreso en plazo que la norma tributaria establece (STC 291/2000, FJ 9); una vez excluido que la medida restrictiva de derechos en que consiste el recargo del $100 \%$ pudiera justificarse como medio para constreñir al cumplimiento de una obligación, en la STC 291/2000 se rechazó asimismo -al igual que se había hecho con anterioridad en relación con el del 50\%- que dicho recargo cumpliera una función indemnizatoria y de estímulo positivo que permitiera excluir la función de castigo propia de las sanciones. Por un lado, tal función no excluía el carácter sancionador de esta medida, pues la cuantía del recargo coincide exactamente con la sanción mínima prevista en el art. 87.1 LGT para las infracciones tributarias graves tipificadas 
en el art. 79 a) LGT, y por ello la aplicación de estos recargos no supone otorgar al contribuyente un trato muy distinto del que le correspondería si se aplicaran las medidas que la propia LGT califica como sanciones. de este modo, al no existir una diferencia importante entre la cuantía del recargo y la de las sanciones, consideramos que este recargo cumplía, además de las otras funciones indicadas, la misma función de castigo que es propia de los actos sancionadores (STC 291/2000, FJ 9); por otro lado, en la STC 267/2000 descartamos que el recargo del 50 por 100 respondiera a otros fines que pudieran excluir su carácter sancionador. $Y$ a la misma conclusión debemos llegar ahora puesto que, si en aquel caso consideramos que al tener el recargo una cuantía del 50 por 100 no podía considerarse que este recargo cumpliera una función de estímulo positivo -la cuantía del recargo coincidía exactamente con la sanción mínima prevista en el art. 87.1 LGT-, en este supuesto, en el que la cuantía del recargo es del 100 por 100, tampoco cabe apreciar que cumpla una función de estímulo positivo que excluya su carácter sancionador, ni se trata de un medio para constreñir al cumplimiento de una obligación, ni, por supuesto, tiene naturaleza tributaria" (STC 291/2000, FJ 10). En definitiva, el recargo del 100\% de la deuda tributaria establecido en el párrafo segundo del art. 61.2 LGT, en su redacción dada por la Ley 18/1991, de 6 de junio, en tanto que supone una medida restrictiva de derechos que se aplica en supuestos en los que ha existido una infracción de la ley y desempeña una función de castigo, no puede justificarse constitucionalmente más que como sanción; para el TG el hecho de que el recargo del 100\% es único, está excluyendo la posibilidad de que se exijan además al contribuyente cualesquiera otros componentes de los que, conforme al art. 58 de la LGT entonces vigente, podían formar parte de la deuda tributaria, y, en particular, los intereses de demora [art. 58.2 b) LGT], las sanciones que pudieran corresponder [arts. 58.2 e) y 87.1 LGT] y, en fin, el recargo de apremio [arts. $58.2 \mathrm{~d}$ )], cuya cuantía era en aquel momento del 20 por 100 (art. 128.4 LGT); asimismo concluye el Tc al igual que los recargos del 10 y del 50 por 100 analizados, respectivamente, en las SSTC 164/1995 y 276/2000 cumplen una función parcialmente indemnizatoria en la medida en que, indudablemente, con su exigencia se pretende también compensar a la Hacienda Pública por el perjuicio que a ésta le supone la no disposición tempestiva de la deuda tributaria, de un lado, así como por los gastos que, en su caso, pudiera originar la incoación de un procedimiento de ejecución forzosa contra los bienes del deudor que no satisface la deuda al mismo tiempo que presenta la declaración extemporánea, de otro; será criterio del TC que la circunstancia de que el recargo único del 
$100 \%$ cumpla otros fines distintos de los punitivos -en particular, una función resarcitoria- ni excluye su función punitiva o de castigo (STC 291/2000, FJ 10), ni permite fragmentarlo atendiendo a las diversas finalidades del mismo. De ahí que en la STC 276/2000, pese a que como ya se señaló que el recargo del 50 por 100 que establecía el art. 61.2, párrafo primero, LGT también cumplía una función resarcitoria en cuanto que uno de sus ingredientes era precisamente el importe de los intereses de demora (FJ 5), declarásemos que aquel recargo, en su totalidad y sin detraer el importe correspondiente a concepto alguno, constituía una sanción, y por las mismas razones procede ahora mantener el mismo criterio en relación con el recargo previsto en el párrafo segundo del art. 61.2 LGT, sin que al TC, en su función de control de la constitucionalidad de la ley, le corresponda decidir sobre la procedencia del pago de intereses de demora y recargo de apremio. Teniendo el recargo del 100\% establecido en el párrafo segundo del art. 61.2 LGT carácter sancionador, procede a continuación comprobar según el TC si su regulación vulnera o no las garantías procesales aplicables a las sanciones que se derivan del art. 24.2 CE, puesto que constituye una doctrina constitucional reiterada desde la STG 18/1981 que los principios esenciales reflejados en el art. 24 de la Constitución en materia de procedimiento han de ser aplicables a la actividad sancionadora de la Administración, en la medida necesaria para preservar los valores esenciales que se encuentran en la base del precepto (FJ 2), así como que tales valores no quedarían salvaguardados si se admitiera que la Administración, por razones de orden público, puede incidir en la esfera jurídica de los ciudadanos imponiéndoles una sanción sin observar procedimiento alguno, $y$, por tanto, sin posibilidad de defensa previa a la toma de la decisión, pues, como se sostuvo en el mismo lugar, la garantía del orden constitucional exige que el acuerdo se adopte a través de un procedimiento en el que el presunto inculpado tenga oportunidad de aportar y proponer las pruebas que estime pertinentes y alegar lo que a su derecho convenga (FJ 3); recordará el TC que a propósito del recargo del $50 \%$ en la STC 276/2000 se llegaba a la conclusión de que el párrafo primero del art. 62.1 LGT vulneraba, efectivamente, las garantías del art. 24.2 CE, pues dados los términos en los que se encontraba regulado, la ley no sólo no preveía expresamente la aplicación de las garantías propias del procedimiento sancionador, sino que, además, su literalidad conducía justo a lo contrario: a su aplicación de plano, lo que fue estimado contrario al art. 24.2 CE y conllevó la declaración de inconstitucionalidad del inciso primero del art. 61.2 LGT; en virtud del mismo criterio, la STC 291/2000 otorgó el amparo solicitado por el recurrente al observar que el recargo no sólo se impuso 'de plano' al deman- 
dante de amparo, esto es, sin observar procedimiento contradictorio alguno y, por tanto, privándole de toda posibilidad de defensa durante la tramitación de este procedimiento, sino que, además la Administración procedió a su ejecución, sin ni siquiera otorgarle la posibilidad de cumplir voluntariamente con el contenido del acto, ya que no sólo no se le notificó debidamente la iniciación del procedimiento de apremio, sino que tampoco se le comunicó la liquidación que a través de dicho procedimiento se ejecutó.... Por todo ello hay que concluir que al haberse impuesto al recurrente un recargo de naturaleza sancionadora sin procedimiento contradictorio alguno, la Administración ha infringido el art. 24.2 CE al no respetar el derecho fundamental del demandante de amparo a no ser sancionado si no es a través del correspondiente procedimiento en el que, con las modulaciones que procedan, se respeten las garantías que se deducen de este precepto constitucional (FJ 12); de esta consideración extraerá el TC, como conclusión, que el recargo del $100 \%$ vulnera el art. 24.2 CE, puesto que no sólo no califica a la medida retributiva que prevé como sanción, ni, por ende, se remite al capítulo VI, sobre infracciones y sanciones, de la LGT, ni a la norma que regula el procedimiento tributario sancionador (durante la vigencia del precepto cuestionado, el Real Decreto 2631/1985, posteriormente, el Real Decreto 1930/1998, y, en la actualidad, el Real Decreto 2063/2004), sino que, al referirse a la misma como recargo y expresar que dicho recargo se exigirá en vía de apremio y será único, dirige derechamente a los ciudadanos afectados, a la Administración actuante y a los órganos judiciales hacia las normas que regulan la liquidación de los tributos, en lugar de, como resultara constitucionalmente preceptivo, a la aplicación de los principios y garantías que para el ámbito sancionador (también, insistimos, para el administrativo sancionador) derivan del art. 24.2 CE (STC 276/2000, FJ 7); en definitiva, concluirá el TC la previsión por parte del precepto cuestionado en este proceso constitucional de un recargo único del $100 \%$ en aquellos casos en los que los obligados tributarios no efectúen el ingreso al tiempo de la presentación de las declaraciones, liquidaciones o autoliquidaciones extemporáneas, sin solicitar expresamente el aplazamiento o el fraccionamiento del pago, supone la definición de una sanción que, al aplicarse sin posibilidad de que el afectado alegue lo que a su defensa considere conveniente y al obviar la declaración de culpabilidad en un procedimiento sancionador que la imposición de toda sanción exige, implica la vulneración del derecho a un proceso con todas las garantías, en este caso, a un procedimiento administrativo sancionador con todas las garantías, reconocido en el art. 24.2 CE y conduce, por tanto, a se deba declarar la inconstitucionalidad y nulidad, con los efectos previstos en el inciso final del art. 40.1 LOTC, del párrafo segundo del art. 61.2 LGT. 


\title{
IV. INSTITUCIONES DEL ESTADO
}

\section{B. Las Cortes Generales.}

\section{Sentencia 31/2011, de 17 de marzo (BOE de 11 de abril). Ponen- te: Gay Montalvo (Recurso de inconstitucionalidad).}

\author{
Preceptos constitucionales: art. 86.1, 149.1.1 y 149.1.13 CE
} otros:

Objeto: Art. 43 y el párrafo octavo de la disposición final segunda del Real Decreto-ley 6/2000, de 23 de junio, de medidas urgentes de intensificación de la competencia en mercados de bienes y servicios.

Materias: Presupuesto habilitante para la adecuada utilización del decreto ley: la posibilidad de enjuiciar esta circunstancia respecto de una específica norma contenida en el mismo.

Será el objeto del presente recurso interpuesto por el Parlamento de Cataluña el art. 43 y el párrafo octavo de la disposición final segunda del Real Decreto-ley 6/2000, de 23 de junio, de medidas urgentes de intensificación de la competencia en mercados de bienes y servicios, relativas a la regulación en materia de horarios comerciales; en él se establece un régimen de libertad de horarios que no será de aplicación hasta que el Gobierno de la Nación conjuntamente con el Gobierno de las Comunidades Autónomas así lo decidan y no antes del día 1 de enero del año 2005, amén de otras medidas relacionadas con ese régimen; dicha nueva regulación se dictan al amparo de lo dispuesto en el art. 149.1.1 y 13 CE. Los recurrentes han planteado la inidoneidad del decreto-ley al poner en cuestión la existencia de la inexorable exigencia de concurrencia del presupuesto habilitante que exige el art. 86.1 CE, al tiempo que se cuestiona la propia existencia de competencia estatal para afrontar esa regulación por razón de la materia, además de argüir la posibilidad de que se estableciera una dualidad regulatoria con sistemas contrapuestos uno de los cuales se formula con carácter supletorio; por ello se considera que el art. 43 no tiene el carácter de norma básica que le atribuye el párrafo octavo de la DF $2^{\mathrm{a}}$, al tiempo que vulnera la competencia exclusiva de la Generalitat de Cataluña en materia de comercio interior; los argumentos en defensa de la norma se centran en la apreciación de la existencia de una situación de urgente necesidad señalando que la misma no puede ser objeto de consideración 
separada sino que la urgencia y necesidad de la misma ha de buscarse en la necesidad de promover un conjunto de medidas de liberalización económica que, para garantizar la continuidad de los resultados económicos, se contienen en diversos Reales Decretos-leyes aprobados en la misma fecha que el que incluye la disposición que ahora se cuestiona; se señala que la regulación de los horarios comerciales obedece a la necesidad de reaccionar al vencimiento, el 1 de enero de 2001, de la regulación transitoria sobre esta materia contenida en la LO 2/1996; se afirma que la regulación estatal en materia de horarios comerciales ha de entenderse dictada al amparo de lo que dispone el art. 149.1.13 CE sin que se haya establecido un régimen supletorio sino una regulación básica alternativa para el supuesto de que la fijada por el art. 43 del Real Decreto-ley no pudiera ser aplicada por falta de desarrollo autonómico de sus previsiones; en definitiva, concluye el TC dos son los vicios de inconstitucionalidad atribuidos a la norma: la no concurrencia del presupuesto habilitante de la extraordinaria y urgente necesidad y la extralimitación competencial del Estado, con la consiguiente invasión de las competencias autonómicas en materia de comercio interior. Comenzará el TC por afrontar la cuestión de la inexistencia del presupuesto habilitante para el ejercicio de la competencia gubernamental de promulgación de un decreto-ley; trayendo en su apoyo lo establecido en la STC 11/2002, FJ 2) su examen ha de ser prioritario en el orden del enjuiciamiento toda vez que ese alegato incide directamente sobre la validez del precepto, cuestionando la legitimidad constitucional de su inclusión en una norma de urgencia como el Real Decreto-ley 6/2000 de modo que, en el caso de ser estimado, resultaría innecesario el examen de las restantes alegaciones ( STC 332/2005, FJ 4); el TC considera como cuestión previa precisar que el examen de la cuestión de la existencia del presupuesto habilitante se lleva a afectos obstante el hecho de que el art. 43 del Real Decreto-ley 6/2000 haya sido derogado por la Ley 1/2004, de 21 de diciembre, de horarios comerciales, sin que ello prive de objeto al presente proceso conforme al criterio ya mantenido por el TC (por todas, STC 189/2005 y doctrina allí citada), en virtud del cual la derogación de dicho art 43 no impide controlar si el ejercicio de la potestad reconocida al Gobierno por el art. 86.1 CE se realizó siguiendo los requisitos establecidos en dicho precepto constitucional; o lo que es lo mismo el compromiso del TC de tratar de velar por el recto ejercicio de la potestad de dictar Decretos-leyes, dentro del marco constitucional, decidiendo la validez o invalidez de las nor- 
mas impugnadas sin atender a su vigencia o derogación en el momento en que se pronuncia el fallo. Estimará el Tc que la concurrencia del supuesto de hecho habilitante requerido por el art. 86.1 CE debe partir de la jurisprudencia constitucional recaída hasta la fecha en relación con este requisito; dicha doctrina ha sido sintetizada en la STC 68/2007, FJ 6, la cual siguiendo pronunciamientos anteriores, señala, tras reconocer el peso que en la apreciación de la extraordinaria y urgente necesidad ha de concederse al juicio puramente político de los órganos a los que incumbe la dirección del Estado, que la necesaria conexión entre la facultad legislativa excepcional y la existencia del presupuesto habilitante conduce a que el concepto de extraordinaria y urgente necesidad que se contiene en la Constitución no sea, en modo alguno, una cláusula o expresión vacía de significado dentro de la cual el lógico margen de apreciación politica del Gobierno se mueva libremente sin restricción alguna, sino, por el contrario, la constatación de un límite jurídico a la actuación mediante decretos-leyes; recordará asimismo el TC que ya ha declarado que es función propia de este Tribunal el aseguramiento de estos límites, la garantía de que en el ejercicio de esta facultad, como de cualquier otra, los poderes se mueven dentro del marco trazado por la Constitución, de forma que el Tribunal Constitucional podrá, en supuestos de uso abusivo o arbitrario, rechazar la definición que los órganos politicos hagan de una situación determinada y, en consecuencia, declarar la inconstitucionalidad de un Decreto-ley por inexistencia del presupuesto habilitante por invasión de las facultades reservadas a las Cortes Generales por la Constitución (SSTC 11/2002, Ff 4 y 137/2003, Ff 3); el TC insistirá en los precedentes de esta doctrina al recordar que ya ha insistido (STC 332/2005, FJ 5) en que el control jurídico de este requisito no debe suplantar a los órganos constitucionales que intervienen en la aprobación y convalidación de los Reales Decretos-leyes, sino que ha de apoyarse en una valoración de conjunto de las circunstancias que rodean al caso; el ejercicio de esta potestad de control del Tribunal implica que la apreciación de la extraordinaria y urgente necesidad que en el caso concurra, sea explícita y razonada y que exista una conexión de sentido entre la situación definida y las medidas que en el Decreto-ley se adoptan (en tal sentido, STC 29/1982, FJ 3); en definitiva dos son los aspectos que conforme a la doctrina del TG (por todas, STG 329/2005, FJ 6) se han de tener en cuenta en la determinación de la concurrencia de la extraordinaria y urgente necesidad exigida por el art. 86.1 CE a efectos de determinar la validez constitucional de la regulación que ahora se examina: En primer lugar, los motivos que, habiendo sido tenidos en cuenta por el Gobierno en su aprobación, hayan sido explicita- 
dos de una forma razonada (SSTC 29/1982, FJ 3; 111/1983, FJ 5; 182/1997, FJ 3 y 137/2003, FJ 4); en segundo lugar, la existencia de una necesaria conexión entre la situación de urgencia definida y la medida concreta adoptada para subvenir a la misma (SSTC 29/1982, FJ 3; 182/1997, FJ 3; 137/2003, FJ 4 y 189/2005, FJ 4). En lo que respecta a la primera de las cuestiones mencionadas, la exigencia de que el Gobierno explicite de forma razonada los motivos que le impulsan a acudir a la figura del Decreto-ley para dar respuesta a una determinada situación, hemos partido tradicionalmente del examen del propio preámbulo del Decreto-ley impugnado, del debate parlamentario de convalidación y de su propio expediente de elaboración para valorar conjuntamente los factores que han llevado al Gobierno a acudir a esta concreta fuente del Derecho (SSTC 29/1982, de 31 de mayo, FJ 4, y 182/1997, de 28 de octubre, FJ 4); aplicando esos dos requisitos, el TC afrontará su examen de la constitucionalidad o no de la exigencia de la inexorable existencia del presupuesto habilitante; apreciará que una de las peculiaridades más importantes del presente caso radica en que la vulneración del presupuesto de hecho habilitante únicamente se imputa a la regulación del régimen de horarios comerciales, pues el Parlamento de Cataluña no ha impugnado el Real Decreto-ley en su totalidad, sino sólo el art. 43, y por conexión con el mismo, el párrafo octavo de la disposición final segunda en cuanto entiende que la motivación de la urgencia y necesidad del propio Real Decreto-ley no puede ser aplicable al precepto impugnado; limitado así el objeto del examen de constitucionalidad, procederá el TC a examinar la existencia del primero de los condicionantes acudiendo a la valoración tanto del preámbulo del Real Decreto-ley 6/2000 como del debate parlamentario de convalidación; en el primero de ellos se señala que la finalidad de la norma es aumentar la capacidad de crecimiento potencial y la productividad de nuestra economía a fin de lograr un ritmo de crecimiento económico que permita continuar aproximando los niveles de renta per cápita y de empleo de España a los de las economías más desarrolladas; la urgencia en la consecución de esas finalidades se justifica en la necesidad de garantizar la permanencia en el tiempo de la fase de expansión económica experimentada por la economía española, mientras que, haciendo ya referencia a la concreta medida adoptada en materia de horarios, se afirma que $E l$ Capitulo V introduce algunas reformas en el sector de la distribución comercial, flexibilizando los horarios comerciales; por lo que se refiere al debate parlamentario se aprecia cómo se destacó por la autoridad guberna- 
mental correspondiente la finalidad de garantizar la continuidad y la profundización de los resultados de la buena situación económica que se perseguía con la adopción de la legislación de urgencia indicando posteriormente que esa urgencia respondía a la necesidad de asentar el crecimiento económico, permitiendo una rápida puesta en marcha de las medidas así como asentar, desde el principio de la legislatura, las expectativas de los ciudadanos y de los mercados respecto a las prioridades de la política económica; en cuanto a la regulación de los horarios comerciales, objeto del presente proceso, se afirma que la adopción de la medida obedece a la percepción del Gobierno acerca de la necesidad de dar respuesta a la cuestión de la implantación de la libertad de horarios prevista para el año 2000, prorrogando hasta el año 2005 el régimen transitorio en materia de libertad de horarios cuyo vencimiento se produciría el 1 de enero de 2001; recordará de nuevo el TC su doctrina respecto al presupuesto de hecho habilitante del Decreto-ley (STC 182/1997, FJ 4) afirmando que al mismo no le corresponde discutir acerca de la bondad técnica, la oportunidad o la eficacia de las medidas impugnadas, debiendo limitarse a examinar la correspondencia entre las mismas y la situación que se pretende afrontar y que constituye el presupuesto para el dictado de la norma tomando a tales efectos en consideración las razones deducidas tanto de la exposición de motivos de la norma cuestionada como del debate parlamentario de convalidación y no obstante haber establecido en ciertos casos la apreciación de la existencia de lo que se ha denominado coyunturas económicas problemáticas (STC 23/1993, FJ 5) para cuyo tratamiento el Decreto-ley representa un instrumento constitucionalmente lícito, ello no es óbice para poder admitir la licitud de esta fuente del derecho en otros supuestos, como el que ahora se analiza que no es otro sino la necesidad de consolidar el crecimiento de la actividad económica que no impide al Gobierno el recurso al Decreto-ley como instrumento normativo adecuado para adoptar medidas de política económica general fundamentadas en garantizar la permanencia en el tiempo de una preexistente fase de expansión económica, lo que habrá de valorarse en atención a las circunstancias que concurran en cada caso concreto; el juicio de la concurrencia del presupuesto habilitador de la norma ha de formularse no sólo en relación con la totalidad del Real Decreto-ley 6/2000, sino con el específico contenido material del art. 43 pues el mismo tiene entidad propia que la hace merecedora en aquel contexto de un tratamiento sistemático diferenciado tanto en el preámbulo como en el articulado del Real Decre- 
to-ley 6/2000 dado que no guarda una relación de absoluta homogeneidad, sistematicidad o necesaria conexión con el resto de las medidas contenidas en la norma; apreciará el TC que es posible deducir que la urgente necesidad que el Gobierno apreció como fundamento para la adopción de la medida ahora cuestionada se fundaba en el doble orden de consideraciones ya aludido y relacionado, en primera instancia, con el carácter flexibilizador de la medida y sus efectos beneficiosos para la consolidación del crecimiento económico y, en segundo lugar, con la necesidad de dar cumplimiento al mandato contenido en la LO 2/1996 en punto a la regulación de los horarios comerciales en el entendimiento de que el régimen transitorio contenido en esa norma se encontraba próximo a perder su vigencia. Considerará el TC que el preámbulo de la norma controvertida no explicita la justificación de la urgencia en la adopción de una regulación como la descrita más allá de afirmar que introduce algunas reformas en el sector de la distribución comercial, flexibilizando los horarios comerciales; tampoco en el debate parlamentario se aportan más detalles respecto a la relación entre esta concreta regulación en materia de horarios comerciales y los objetivos de consolidación de la continuidad y la profundización de los resultados de la favorable situación económica que el Gobierno perseguía con su adopción; aun cuando apreciar si una determinada situación reviste las notas de extraordinaria y urgente necesidad que justifica el establecimiento de una norma por Decreto-ley es una tarea que corresponde, en principio, al Gobierno y para la cual ha de gozar de un razonable margen de discrecionalidad en la apreciación de dicha urgencia, lo que pudiera conducir a considerar que la flexibilización y liberalización de los horarios comerciales, en tanto que medida de impulso de la economía, pudiera justificar el uso del Decreto-ley, lo cierto es que dicho margen no le autoriza, sin embargo, para incluir en el Decreto-Ley cualquier género de disposiciones; por ello se obliga el TC a comprobar, en concreto, ahora la existencia del segundo elemento de exigencia, esto es, la necesaria conexión de sentido entre la medida concretamente impugnada y la situación de urgencia explicitada por el Gobierno a la que se pretendía responder con su aprobación, lo que le nos llevará a examinar la concreta justificación aportada; en ese sentido es de señalar que, ante el silencio del preámbulo de la norma, no son numerosas las referencias a esta cuestión contenidas en el debate de convalidación del Real Decreto-ley 6/2000 pues en dicho debate únicamente se señala la necesidad de adoptar una prórroga hasta el año 2005 del régimen transitorio de 
libertad de horarios fijado en 1995; continuando con su argumentación, señalará el TC que en nada afecta que esta última regulación fuera ya enjuiciada en la STC 124/2003, por cuanto, además de que en la misma ya se apreció el carácter no orgánico de los arts. 2 y 3 de la Ley Orgánica 2/1996, el examen que ahora se realiza irá dirigido a comprobar la concurrencia del presupuesto alegado por el Gobierno para recurrir a la vía de urgencia para aprobar la regulación de los horarios comerciales; desde este punto de vista más concreto, relacionado con la existencia de una necesidad extraordinaria y urgente a la que la inmediata entrada en vigor de la medida vendría a dar respuesta, no es posible apreciar fundamento para la adopción de una regulación como la aquí impugnada el régimen vigente establecido en ese momento que es analizado pormenorizadamente por el TC le lleva a concluir que ningún vacío normativo había de producirse ya que el ya citado art. 3 era de aplicación hasta que procediera su sustitución por el régimen de libertad horaria, conforme a las formalidades previstas en el referido precepto legal, esto es previo acuerdo del Gobierno de la Nación con cada una de las Comunidades Autónomas adoptado no antes de 1 de enero de 2001, o, lo que es lo mismo, en cualquier momento posterior a dicha fecha de modo que, entretanto, continuarían vigentes las referidas reglas del art. 3 sin, en principio, límite temporal alguno; dicho de otro modo, el conjunto de reglas específicas contenidas en la legislación estatal de horarios comerciales no perdía su vigencia por el mero transcurso del tiempo sino que, por el contrario, la propia norma determinaba su vigencia al afirmar que $[h]$ asta que proceda, de acuerdo con lo establecido en el presente artículo, la aplicación del mencionado régimen (el de plena libertad horaria del art.2), regirán las siguientes reglas"; frente a lo señalado por el Gobierno, el 1 de enero de 2001 no expiraba ningún régimen transitorio en materia de horarios comerciales. Constatada por el TC la inexistencia de un vacío normativo que fundamentase la necesidad de una apremiante actuación legislativa en esta materia resulta además que la efectividad de la anunciada libertad de horarios quedaba diferida, al menos, hasta el año 2005 lo cual supone, en sí mismo, una contradicción con el uso del Decretoley para establecer esa libertad y, en la medida en que ni siquiera era posible determinar el momento de su entrada en vigor, las eventuales decisiones que pudieran adoptarse por los distintos agentes económicos en función de la misma tenían un alcance limitado, extremos ambos que diferencian este supuesto del examinado en la STC 189/2005, FJ 5; en definitiva, se apreciará por TC que en el pre- 
sente caso la medida fue tomada seis meses antes de que acabara el plazo, teniendo el legislador en su mano el procedimiento legislativo ordinario, ya que, como antes se señaló, dicho plazo no era una fecha ineluctable de finalización de vigencia, lo que hacía que tuviese en sus manos tiempo suficiente para realizar el cambio normativo sobre horarios comerciales que estimase oportuno a través del procedimiento legislativo ordinario sin necesidad de acudir a la vía del Decreto-ley; aducirá, además el TC su doctrina ya señalada en la STC 124/2003, FJ 9, a cuyo tenor los cambios en la regulación aplicable no resultan de gran relevancia de modo que, aplazada la efectiva implantación de la libertad horaria, no existe un tratamiento novedoso de la materia respecto a la regulación sustantiva a la que las reglas del art. 43 venían a sustituir; en consecuencia tampoco desde el punto de vista de la necesidad de introducir una innovación normativa efectiva (STG 332/2005, FJ 7), se aprecia la nota de imprevisibilidad que define la existencia de una necesidad extraordinaria a la que ha de hacerse frente a la misma en un plazo más breve del que requeriría la tramitación urgente de una eventual reforma legislativa. Se concluye, en atención a todo lo señalado que en el caso de la norma que ahora se analiza, el Gobierno no ha aportado justificación suficiente que permita apreciar la existencia de la situación habilitante requerida por el art. 86.1 CE, pues no hay conexión de sentido entre la situación de urgencia y la medida en materia de horarios comerciales adoptada para afrontarla o, en otros términos, la necesaria adecuación entre la medida impugnada y la situación de urgencia a la que se desea hacer frente con la misma, lo que, en conclusión, determina que la utilización de la figura del Decreto-ley para regular, en los términos antes expuestos, los horarios comerciales constituya un supuesto de uso abusivo y arbitrario de esa figura; a la vista de las circunstancias y las razones expuestas el TC estima deber concluir que, en el caso del art. 43 del Real Decreto-ley 6/2000, el Gobierno no ha aportado una justificación bastante que permita apreciar la concurrencia del presupuesto habilitante requerido, por lo que no cabe sino declarar inconstitucional y nulo el citado precepto por vulneración del art. 86.1 CE, mientras que la impugnación del párrafo octavo de la disposición final segunda decae al anularse el art. 43. Por todo ello se estima el presente recurso de inconstitucionalidad y, en consecuencia, se declara que el art. 43 del Real Decreto-ley 6/2000, de medidas urgentes de intensificación de la competencia en mercados de bienes y servicios, es inconstitucional y nulo. 


\title{
VI. ORGANIZACIÓN TERRITORIAL DEL ESTADO
}

\section{A. Comunidades Autónomas.}

\section{A.1. Autonomía.}

\section{Sentencia $1 / 2011$, de 14 de febrero (BOE de 15 de marzo). Po- nente: Pérez Tremps (Conflicto positivo de competencia y recurso de inconstitucionalidad).}

\author{
Preceptos constitucionales: $43 ; 149.1 .1$ y 149.1 .16
} otros: arts. 71.55, 71.30 y 77.1 del EAAr de 2007

Objeto: Conflictos positivos de competencia núms. 4824-2002, 4825-2002, 4826-2002, 4827-2002 y 4828-2002, acumulados por Auto del Pleno del Tribunal Constitucional 246/2002, de 26 de noviembre, promovidos por la Diputación General de Aragón contra diversos convenios de colaboración en materia de formación continuada de las profesiones sanitarias, y en el recurso de inconstitucionalidad núm. 1065-2004, planteado por la Diputación General de Aragón contra diversos artículos de la Ley 44/2003, de 21 de noviembre, de ordenación de las profesiones sanitarias, acumulado a los anteriores procesos por Auto de la Sala $2^{a}$ 195/2009, de 29 de junio

Materias: Competencia estatal de coordinación general de la sanidad; trato igual de los profesionales sanitarios en todo el territorio nacional; actuaciones de formación continua de los trabajadores ocupados: integración en la materia legislación laboral. Competencias en relación con la materia de sanidad: Las actuaciones de acreditación, expedición de certificados y emisión de informes de evaluación y supervisión ha de ser realizadas en su territorio por la Comunidad Autónoma. Derecho a la salud.

El TG debe dar respuesta a seis procesos instados por la Diputación General de Aragón, que plantea cinco conflictos positivos de competencia contra otros tantos Convenios de colaboración suscritos por el Ministerio de Educación, Cultura y Deporte, el Ministerio de Sanidad y Consumo, y los respectivos Consejos Generales de los Colegios de determinadas profesiones sanitarias (veterinarios, médicos, odontólogos y estomatólogos, farmacéuticos y diplomados de enfermería) y un recurso de inconstitucionalidad, contra el art. 35.1 y 4 y la DF $1^{a}$ de la Ley 44/2003, de ordenación de las profesiones sanitarias. Como se señaló en el Auto que ha acordado la acumula- 
ción de todos estos procesos (ATC 195/2009, de 29 de junio), la causa petendi y los títulos competenciales aducidos por las partes en defensa de su posición han sido en todos los casos los mismos; para el Gobierno de la Comunidad Autónoma de Aragón los convenios y los preceptos legales impugnados reconocen a la Administración General del Estado competencias ejecutivas en el ámbito de la formación continuada de las profesiones sanitarias que le permiten encomendar algunos aspectos de su gestión a los Consejos Generales de los respectivos Colegios profesionales, vulnerando con ello las competencias autonómicas en el ámbito de la sanidad, la gestión de la asistencia sanitaria de la Seguridad Social, los Colegios profesionales y el ejercicio de las profesiones tituladas [arts. 35.1.40, 39.1.1 y 35.1.22, respectivamente, todos ellos del Estatuto de Autonomía de Aragón (EAAr) de 1982]. Por su parte, el representante del Gobierno de la Nación considera que todas las disposiciones recurridas se encuentran amparadas por la competencia estatal de coordinación general de la sanidad (art. 49.1.16 CE) y por lo contemplado en el art. 149.1.1 CE, que garantizaría un trato igual de los profesionales sanitarios en todo el territorio nacional. Será criterio del TC que la resolución conjunta de estos procesos debe iniciarse con la consideración de cuál deba ser su parámetro de control, al resultar necesario pronunciarse sobre la incidencia que haya podido tener en los mismos la reforma del Estatuto de Autonomía de Aragón llevada a cabo por la Ley Orgánica 5/2007, en la medida en que la misma haya afectado a las competencias asumidas por la Comunidad Autónoma que ésta considera vulneradas: las competencias en materia de sanidad, Colegios profesionales y ejercicio de las profesiones tituladas y gestión de la asistencia sanitaria de la Seguridad Social; apreciará el TC que la peculiaridad del supuesto actual es que, a diferencia de lo sucedido en otros supuestos, en los que la vigencia de la norma impugnada estaba limitada a un ejercicio presupuestario (SSTC 237/2007, 238/2007 y 248/2007), en el presente resulta aplicable su doctrina sobre el ius superveniens, según la cual el control de las normas que incurren en un posible exceso competencial debe hacerse de acuerdo con las normas del bloque de la constitucionalidad vigentes en el momento de dictar Sentencia [entre otras, SSTC 137/1986, FJ 4 y 135/2006, FJ 3 a)]. Aunque la cláusula segunda de los convenios de colaboración prevé que su duración inicial era de tres años, la posibilidad de prorrogarlos tácitamente, la vigencia en principio ilimitada de los preceptos legales impugnados y la pervivencia de la situación conflictual en tanto que la 
parte actora mantenga la solicitud del pronunciamiento del TC, son todos, aspectos que llevan al TC a analizar su constitucionalidad a la luz de la delimitación de competencias que se deriva de la reforma del Estatuto de Aragón; advirtiendo que esta reforma no ha introducido cambios sustanciales en las competencias aducidas por la representación del Gobierno autonómico (arts. 71.55, 71.30 y 77.1, respectivamente, todos del EAAr de 2007). Apreciará el TC la necesidad de delimitar el objeto de su enjuiciamiento, toda vez que no existe una completa correspondencia entre la impugnación formal que hace la parte actora de los convenios y de la Ley 44/2003 y el alcance material de las tachas que se les formulan; en cuanto a los convenios de colaboración, se impugnan en su totalidad, pero los escritos de alegaciones centran la controversia exclusivamente en las potestades de gestión que respecto de la formación continua de las distintas profesiones sanitarias se atribuyen al Estado, con especial incidencia, pero no sólo, en aquellas actuaciones que se encomiendan por aquél a los correspondientes Consejos de Colegios profesionales; el objeto litigioso relativo a dichos convenios de colaboración ha de quedar circunscrito al ámbito de las funciones ejecutivas recogidas en las cláusulas siguientes: primera; segunda, epígrafe e); cuarta; y quinta, por lo que concluye el TC, las restantes cláusulas han de quedar fuera del objeto de su enjuiciamiento en la medida que contemplan actuaciones normativas o de coordinación atribuidas a órganos del Estado [caso de la cláusula segunda, epígrafes a), b), c) y f)], o incluso, de alguna función ejecutiva que no se discute expresamente, y sobre la que nada se argumenta [epígrafe d) de dicha cláusula segunda] y respecto de las cuales no se formulan reproches sustentados en la correspondiente argumentación. Por lo que se refiere a la Ley 44/2003, aunque el Gobierno aragonés impugna el art. 35.1 y 4 y la DF $1^{\text {a }}$ en su totalidad, será criterio del TC que el objeto de control debe quedar circunscrito al primer párrafo del art. 35.1, primer párrafo, y 35.4, primer párrafo, que se refieren a la acreditación de la formación continuada y a la delegación de las funciones de gestión y acreditación en otras corporaciones de derecho público, así como al primer apartado de la DF $1^{\text {a }}$, que ampara la competencia estatal en el art. 149.1.1 y $16 \mathrm{CE}$; los restantes contenidos normativos del art. 35.1 y 4 y de la DF $1^{\text {a }}$ deben entenderse excluidos del recurso al referirse a aspectos sobre los que no se formula reproche alguno. Entrará a analizar el TC, en primer lugar, los cinco convenios de colaboración impugnados, convenios que regulan con un contenido idéntico diversos aspectos de la formación 
continua del personal de los veterinarios, médicos, odontólogos y estomatólogos, farmacéuticos y diplomados en enfermería. Se entiende por el Gobierno de Aragón que en dichos convenios se contemplan actuaciones o medidas de carácter ejecutivo relativas a la formación continua de dicho personal sanitario que corresponde realizar a la Comunidad Autónoma de Aragón en su territorio, en razón a las competencias asumidas por dicha Comunidad Autónoma en las materias de sanidad, Colegios profesionales y ejercicio de las profesiones tituladas y gestión de la asistencia sanitaria de la Seguridad Social (art. 71.55, 71.30 y 77.1, respectivamente, del EAAr de 2007). Esas competencias resultarían vulneradas en la medida en que tales actuaciones de gestión se atribuyen, según los convenios impugnados, al Estado o se encomiendan por éste a los órganos superiores de las organizaciones colegiales implicadas en cada caso, desconociendo con ello el Convenio de Conferencia Sectorial de 15 de diciembre de 1997 del Consejo Interterritorial del Sistema Nacional de Salud sobre formación continua de las profesiones sanitarias, que reconocía a las Comunidades Autónomas las actividades de gestión en esta materia, teniendo sus actuaciones valor en todo el Sistema Nacional de Salud. Por el contrario la representación del Estado, los convenios objeto de conflicto no se contraponen a los principios previstos en el Convenio de 15 de diciembre de 1997, que contemplaba que la Comisión de Formación Continuada estableciera un sistema coordinado de pautas y criterios comunes en esta materia, de acuerdo con el principio de libre configuración de cada titular para establecer su propio sistema de acreditación, sistema que no es excluyente; de otra parte, el carácter no excluyente de la acreditación permite que los órganos de representación institucional y corporativa de las distintas profesiones sanitarias se incorporen a las actividades de formación continua de las mismas a través de la técnica de la encomienda de gestión, lo que resulta aconsejable por no disponer las Administraciones territoriales de los medios idóneos y sin que dicha encomienda suponga cesión alguna de competencia; en definitiva, no puede reivindicarse una concepción excluyente del sistema de acreditación de la formación continua, pues ello situaría la polémica en el ámbito del art. 149.1.30 CE y no, como es el caso, en el de la sanidad (art. 149.1.16 CE). nos encontramos ante una acción típica de la coordinación sanitaria que se basa en la naturaleza no reglada de la formación, la participación de la Administración institucional y en el carácter no excluyente de la acreditación. Ante este antagonismo, procederá el TC a encuadrar las actuacio- 
nes que son propias de la formación continua de los profesionales sanitarios, teniendo en cuenta que, según la cláusula segunda de los convenios impugnados corresponde al Estado, a través de los Ministerios intervinientes, regular el sistema estatal de acreditación de la formación continuada de las profesiones sanitarias y entre otras acciones: aprobar los planes de formación sanitaria, con indicación de criterios generales sobre las enseñanzas técnicas y prácticas adecuadas, establecer los supuestos y formas de revalidar periódicamente los conocimientos y aptitudes para el ejercicio de las profesiones sanitarias y reconocer u homologar los títulos, certificados, diplomas, etc., que otorguen otras instituciones nacionales o extrajeras. Reconociendo el TC que estas cuestiones quedan fuera del objeto de conflicto, entiende, al tiempo, que son relevantes para realizar el encuadramiento competencial de las cuestiones debatidas en estos procesos; entenderá, por ello, que también hay que tener en cuenta que los aspectos más directamente implicados en la controversia son actuaciones instrumentales de las previsiones de la cláusula segunda antes reproducidas: acreditación de enseñanzas, expedición de certificados o diplomas acreditativos de las enseñanzas impartidas y emisión de informes a los efectos de evaluación y supervisión de las actividades previstas en el convenio; por ello, la formación continuada de estas profesiones sanitarias se proyecta sobre profesionales que ya disponen de la titulación académica requerida para el ejercicio de su profesión, de manera que la formación se dirige a actualizar y mejorar las aptitudes necesarias para el desempeño de cada profesión. Entenderá el TC que se encuentra ante supuestos que tienen como objeto promover la actualización permanente de los conocimientos profesionales; es decir, como ya se dijo en la STC 95/2002, considera el TC que se encuentra ante un supuesto de formación continua de los trabajadores asalariados; recordará por eso el TC que ya en la citada Sentencia se declaró que la materia de formación profesional ocupacional en su modalidad de formación continua de los trabajadores asalariados o en activo no pertenece al ámbito de la educación... Baste para ello tener en cuenta, como aduce con acierto el representante procesal del Gobierno, que la formación profesional ocupacional, a diferencia de la formación profesional reglada, no forma parte del sistema educativo, en el que los saberes o cualificación con base en aptitudes especificas se imparten y están dirigidos, previa estratificación en niveles y grados, a la obtención de títulos académicos o profesionales que habilitan para el ejercicio de determinadas profesiones u oficios... En suma, ha de discernirse entre la formación profesional reglada que, en cuanto perteneciente o integrada en el sistema educativo, es materia susceptible de encuadramiento en el titulo competencial autonómico de 'regulación y administración de la enseñanza' (art. 15 
EAC) y la materia aquí controvertida, que al comprender las acciones formativas para la formación continua de los trabajadores ocupados no forma parte del sistema educativo (STC 95/2002, FJ 6)(STC 190/2002, FJ 5); coherentemente con ese criterio, recordará el TC cómo en las SSTC 95/2002, FJ 8, y 190/2002, FJ 6, encuadra las actuaciones de formación continua de los trabajadores ocupados en la materia legislación laboral (art. 149.1.6 CE); traerá en su apoyo el TC la distinción que ya se encontraba en la STC 190/2002 entre las acciones formativas de los trabajadores ocupados, que incardinó en la señalada materia de legislación laboral y las acciones de formación continua en las Administraciones públicas ya que las acciones formativas que se realicen en el seno de estas Administraciones deberán encuadrarse, desde la perspectiva del orden constitucional de competencias, en las materias 'bases... del régimen estatutario de sus funcionarios' o 'legislación laboral', según que la relación de los empleados públicos con la Administración sea de carácter funcionarial, estatutario o laboral. Pues bien, en la primera de estas materias al Estado le corresponde dictar la normativa básica (art. 149.1.18 CE)" (STC 190/2002, FJ 8; considerará el TC que en concordancia con todo ello, en dichas SSTC 95/2002 y 190/2002 ya quedó determinado que las medidas de formación continua allí examinadas debían respetar las competencias de ejecución de las Comunidades Autónomas en dichas materias de legislación laboral y de régimen estatutario de los funcionarios. En base a esta doctrina, considerará el TG respecto de las actuaciones que se controvierten en estos procedimientos acumulados, que al dirigirse aquéllas a la formación continua de determinadas profesiones sanitarias, debe descartar también en este supuesto que las mismas se incardinen en la materia educación, al apreciar que no se ha establecido un sistema de retitulación dentro del sistema educativo general para la formación continua de estos profesionales; muy al contrario, puesto que la formación de los mismos tiene obvia repercusión en el ámbito de la salud humana [arts, 18.14 de la Ley 14/1986, general de sanidad y 12 f) de la Ley 44/2003, de ordenación de las profesiones sanitarias] debe concluir que los Convenios controvertidos se incardinan en la materia sanidad, en la que el Estado tiene atribuida la competencia para el establecimiento de las normas básicas y coordinación (art. 149.1.16 CE) y la Comunidad Autónoma de Aragón la competencia exclusiva respetando lo dispuesto en el art. 149.1 de la Constitución (art. 71.55 EAAr), esto es, respetando las bases y la coordinación dictadas por el Estado en dicha materia. Rechazará el TC la incidencia del art. 149.1.1 CE respecto de las cláusulas de los convenios que atribuyen al Estado potestades de eje- 
cución objeto de encomienda, toda vez que dicho precepto constitucional (regulación de las condiciones básicas...), tiene un alcance normativo, lo que permite al Estado una regulación, aunque limitada a las condiciones básicas que garanticen la igualdad, que no al diseño completo y acabado de su régimen jurídico [STC 188/2001, FJ 12, con cita de la STC 61/1997, FJ 7 b)], mientras que la controversia delimitada en el presente caso se refiere a actuaciones del ámbito aplicativo, de ejecución. Apreciará el TC que ambas partes del proceso esgrimen el Convenio de Conferencia Sectorial de 15 de diciembre de 1997: en ese sentido indica que dicho convenio, que no fue impugnado ante el TC y que por tanto no puede merecer ningún juicio de adecuación al orden constitucional de competencias, en modo alguno puede erigirse en parámetro de constitucionalidad de los convenios de colaboración impugnados, pues dicho parámetro sólo está conformado por las normas del bloque de la constitucionalidad implicadas, en el caso, por la Constitución y el Estatuto de Autonomía de Aragón. Tras recordar el contenido de las cláusulas de los convenios controvertidos, el TC recordará lo ya expuesto en el FJ 4 de esta Sentencia al considerar que las actuaciones de acreditación, expedición de certificados y emisión de informes de evaluación y supervisión ha de ser realizadas en su territorio por la Comunidad Autónoma de Aragón; constatada la naturaleza ejecutiva de las funciones que se atribuyen a las organizaciones colegiales y de acuerdo con el reparto competencial existente en el bloque de la constitucionalidad en el momento presente en la materia de sanidad, dichas funciones son competencia, en principio, de la Comunidad Autónoma de Aragón cuando hayan de realizarse en su territorio; no obstante el TG se plantea asimismo la necesidad de valorar si la previsión que contiene el encabezamiento de la cláusula primera, relativa a que las funciones en cuestión se realicen a nivel estatal, puede determinar, por el alcance supraautonómico de aquéllas, que la atribución a las representaciones nacionales de las organizaciones colegiales resulte legítima; el TG rechaza la oposición del Abogado del Estado que se opone a la vulneración de la competencia autonómica aduciendo el carácter no excluyente de la acreditación pública de las actividades de formación continuada, pues las funciones materiales objeto de debate son encomendadas (art. 15.1 de la Ley 30/1992) a los Consejos de Colegios por la Administración General del Estado, a través de los Ministerios de Educación, Cultura y Deporte y de Sanidad, Ministerios que con tal encomienda no hacen cesión de competencia alguna y, consecuentemente, retienen las potestades públicas rela- 
tivas a la resolución de los recursos y reclamaciones que en su caso se interpongan, según reza la cláusula cuarta de estos convenios; conluirá el TC: por tanto, nos encontramos ante un ejercicio de poder público por parte del Estado, algunas de cuyas actuaciones meramente materiales se encomiendan a las organizaciones colegiales de carácter nacional, lo que, en principio, legitima la reivindicación competencial de la Comunidad Autónoma de Aragón. Considera el TC que debe insistir en que la posible eficacia supracomunitaria de los actos de ejecución está implícita en las reglas constitucionales del reparto competencial en atención a que la unidad política, jurídica económica y social de España impide su división en compartimentos estancos y, en consecuencia, la privación a las Comunidades Autónomas de la posibilidad de actuar cuando sus actos pudieran originar consecuencias más allá de sus límites territoriales equivaldría necesariamente a privarlas, pura y simplemente de toda capacidad de actuación (STC 37/1981, de 16 de noviembre, Ff 1) (STC 31/2010, FJ 63); recordará el TC que ya ha afirmado que las actuaciones ejecutivas autonómicas, por el hecho de que generen consecuencias más allá del territorio de las Comunidades Autónomas que hubieren de adoptarlas, por estar asi previsto en sus Estatutos de Autonomía, no revierten al Estado como consecuencia de tal efecto supraterritorial, pues a este traslado de la titularidad, ciertamente excepcional, tan sólo puede llegarse, como se apuntó en la STC 329/1993 (FF 4), cuando, además del alcance territorial superior al de una Comunidad Autónoma del fenómeno objeto de la competencia, la actividad pública que sobre él se ejerza no sea susceptible de fraccionamiento y aun en este caso, dicha actuación no pueda llevarse a cabo mediante mecanismos de cooperación y coordinación, sino que requiera un grado de homogeneidad que sólo pueda garantizar su atribución a un solo titular, que forzosamente deba ser el Estado, o cuando sea necesario recurrir a un ente con capacidad de integrar intereses contrapuestos de varias Comunidades Autónomas (STC 243/1994, Ff 6) (SSTC 175/1999, FJ 6, y 223/2000, FJ 11). Considerará el TC que en el caso controvertido no se han aportados datos o argumentos que permitan apreciar que las actuaciones controvertidas deban ser necesariamente realizadas por el Estado (y encomendadas a las organizaciones colegiales de ámbito nacional) y, como consecuencia de ello, calificadas de básicas; concluirá el TC que la cláusula primera de los convenios de colaboración impugnados vulnera las competencias asumidas por la Comunidad Autónoma de Aragón en materia de sanidad. Por lo que se refiere a las restantes cláusulas de los controvertidos convenios, considerará el TC que la cláusula segunda, epígrafe f), vulnera también las competencias de la Comunidad Autónoma de Aragón, pues la evaluación y supervisión de las 
actuaciones encomendadas son también actuaciones aplicativas de mera ejecución, que deben ser realizadas por dicha Comunidad $\mathrm{Au}-$ tónoma. La cláusula tercera infringe las competencias de Aragón al prever que los órganos colegiales realicen las funciones encomendadas. La cláusula cuarta, que contempla los límites de la encomienda de gestión y la atribución de la resolución de recursos y reclamaciones a los Departamentos ministeriales que suscriben los convenios, también conculca las competencias autonómicas por los mismos motivos antes expuestos. La cláusula quinta será considerada, asimismo, contraria al orden de competencias al atribuir a las organizaciones colegiales nacionales la elaboración de un informe anual sobre sus actividades en esta materia; dicho informe debe ser emitido por la Comunidad Autónoma. Por,lo que se refiere a los preceptos impugnados de la Ley 44/2003, una vez delimitados en cuanto a su objeto procesal en los términos expuesto en el FJ 3, considera el TC que, la representación de la Comunidad Autónoma considera que los preceptos recurridos buscan que tanto el Estado como las Comunidades Autónomas ejerzan potestades ejecutivas paralelas que les permitan formalizar después las correspondientes delegaciones, ejercicio paralelo de competencias que sólo es posible en los casos constitucionalmente previstos, como el del art. 149.2 CE. Por tanto, reclama para la Comunidad de Aragón las competencias de ejecución previstas en los preceptos recurridos. Por su parte, la representación del Estado defiende la competencia del Estado con argumentos similares a los sustentados respecto de los convenios de colaboración impugnados que ya han sido examinados. Abordará el TC la cuestión, en primer lugar, determinando el alcance de los títulos habilitantes del Estado. Se reitera el TC en lo ya establecido en el FJ 6 de esta STC: el art. 149.1.1 CE no otorga cobertura a las actuaciones de acreditación de actividades y programas de actuación en materia de formación continuada de los profesionales sanitarios (art. 35.1), por ser actividades de naturaleza aplicativa o ejecutiva; lo propio acaece respecto de la delegación de las mismas (art. 35.4. En este caso, el derecho constitucional implicado es el derecho a la salud (art. $43 \mathrm{CE}$ ), derecho que ciertamente se relaciona con la formación adecuada de los profesionales sanitarios; tendrá en cuenta el TC que el art. 149.1.1 CE, aunque habilita al Estado para el establecimiento de las condiciones básicas que tienden a garantizar la igualdad en el ejercicio de los derechos constitucionales, no lo hace para establecer una normación completa y acabada del derecho de que se trate, sino tan sólo a lo atinente al contenido primario (STC 154/1988) 
del derecho, a las posiciones jurídicas fundamentales (facultades elementales, limites esenciales, deberes fundamentales, prestaciones básicas, ciertas premisas o presupuestos previos) (STC 188/2001, FJ 12); los arts. 35.1 y 4 no se refieren a los señalados aspectos centrales del contenido primario del derecho a la salud, puesto que se refieren a actuaciones aplicativas de criterios más generales y abstractos sobre la formación continuada del personal sanitario regulados en los arts. 33 y 34 de la Ley 44/2003, criterios que, a su vez, precisan de concreción normativa; el art. 35.1 y 3 no encuentra cobertura competencial en el art. 149.1.1 CE; concluye el TC que hay que recordar aquí lo que ya dijo al examinar la relación existente entre el art. 149.1.1 CE y el derecho a disfrutar de una vivienda digna (art. $47 \mathrm{CE}$ ), que este último precepto no constituye por sí mismo un título competencial autónomo en favor del Estado, sino un mandato o directriz constitucional que ha de informar la actuación de todos los poderes públicos (art. 53 de la Constitución) en el ejercicio de sus respectivas competencias, por lo que las facultades del Estado para garantizar el derecho a disfrutar de una vivienda digna las debe instrumentar aquél mediante sus competencias sobre las bases y coordinación de la planificación económica del subsector vivienda y sobre las bases de ordenación del crédito (STC 152/1988, FJ 2); en atención a ese precedente considera el TC que debe valorar si las potestades ejecutivas del Estado que se discuten encuentran soporte en la competencia del Estado para establecer la normativa básica y la coordinación en materia de sanidad (art. 149.1.16 CE), considerando que corresponde a la Comunidad Autónoma de Aragón la competencia exclusiva en dicha materia respetando las indicadas competencias del Estado (art. 71.55 EAAr); se remitirá el TC a los argumentos esgrimidos ya en los FFJJ 6 y 7 donde ya rechazó los mismos alegatos del Abogado del Estado en defensa de la competencia estatal; considerará que aunque con carácter excepcional determinados actos de ejecución puedan tener naturaleza básica por ser complemento necesario de la propia normativa básica (STC 197/1996, FJ 5, con cita de otras), tal criterio no puede ser admitido respecto de la acreditación de actividades y programas de formación continuada y de los centros en que se impartan, puesto que la normativa básica estatal puede establecer los requisitos que deben cumplir tales actividades, programas y centros y, tras ello, las Comunidades Autónomas otorgarán las acreditaciones correspondientes con sujeción a dicha normativa básica; tampoco la competencia de coordinación sanitaria ex art. 149.1.16 CE otorga al Estado la competencia para realizar por sí mismo dichas acreditaciones, ya que la coordinación, por su propio 
alcance, no permite desplazar las competencias autonómicas de ejecución (por todas, STC 194/2004, FJ 8); será criterio del TC que nos encontramos ante potestades de naturaleza ejecutiva que son, por ello, de la competencia de la Comunidad Autónoma de Aragón; para añadir que las previsiones del art. 35.1 y 4, consistentes en atribuir de modo genérico e indistinto tanto al Estado como a las Comunidades Autónomas las potestades de acreditación y su posibilidad de delegación en otras corporaciones o instituciones de Derecho público, previendo que tanto las acreditaciones estatales como las autonómicas tengan efectos en todo el territorio nacional (párrafo segundo del art. 35.1, no incluido en el objeto del proceso al no objetarlo la parte recurrente), además de alterar el sentido que la Constitución da a las competencias compartidas, en este caso la del art. 149.1.16 CE, comporta la indeseada consecuencia de duplicar actuaciones administrativas similares, lo que contradice la doctrina del TC, que ya afirmó la necesidad de evitar duplicidades burocráticas o el mantenimiento de Administraciones paralelas (STC 79/1992, FJ 4, con cita de las SSTC 187/1988, FJ 12 y 13/1992, FJ 7). Concluirá el TC que las competencias del Estado de acreditación en materia de formación continuada de los profesionales sanitarios, reguladas por el art. 35.1, primer párrafo, y 4, primer párrafo, de la Ley 44/2003, son inconstitucionales por vulnerar el art. 149.1.16 CE. El TC estima parcialmente los conflictos positivos de competencia y el recurso de inconstitucionalidad planteados por la Diputación General de Aragón y, en consecuencia, declara:

- la inconstitucionalidad y consiguiente nulidad de las cláusulas primera; segunda, epígrafe e); cuarta; y quinta de los convenios de colaboración en materia de formación continuada de las profesiones sanitarias celebrados entre los Ministerios de Educación, Cultura y Deporte, y de Sanidad y Consumo y los Consejos Generales de Colegios de Veterinarios, Médicos, Odontólogos y Estomatólogos, Farmacéuticos y Diplomados en Enfermería suscritos los días 8 y 15 de febrero de 2002.

- la inconstitucionalidad y consiguiente nulidad de los incisos "El Ministerio de Sanidad y Consumo" y "en el ámbito de sus respectivas competencias" del primer párrafo de los art. 35.1 y 35.4 de la Ley 44/2003, de 21 de noviembre, de ordenación de las profesiones sanitarias. 


\section{Sentencia 4/2011, de 14 de febrero (BOE de 15 de marzo). Po- nente: Aragón Reyes (Guestión de constitucionalidad).}

Preceptos constitucionales: 38, 131 y 149.1.6, 149.1.11 y 149.1.13. otros:

Objeto: Cuestión de inconstitucionalidad núm. 7559-2006, planteada por la Sección Quinta de la Sala de lo Contencioso-Administrativo del Tribunal Superior de Justicia de Cataluña respecto del art. 34.1 del Decreto Legislativo de la Generalitat de Cataluña 1/1993, de 9 de marzo, sobre comercio interior, por el que se aprueba la refundición en un texto único de los preceptos de la Ley 1/1983, de 18 de febrero, y la Ley 23/1991, de 29 de noviembre.

Materias: Competencias exclusivas del Estado en materia de legislación mercantil

Se plantea cuestión de inconstitucionalidad en relación con el art. 34.1 del Decreto Legislativo de la Generalitat de Cataluña 1/1993, de 9 de marzo, sobre comercio interior, en el inciso o unas condiciones especiales de estos que supongan su aminoración en relación con los precios practicados habitualmente, por posible infracción de lo dispuesto en el art. 149.1.6 CE, que atribuye competencia exclusiva al Estado en materia de legislación mercantil, y en el art. 24.1 de la Ley 7/1996, de 15 de enero, de ordenación del comercio minorista; la cuestión planteada estriba en determinar si el referido inciso final del art. 34.1 del Decreto Legislativo de la Generalitat de Cataluña 1/1993, de 9 de marzo, sobre comercio interior, al regular la venta en rebajas, ha incidido sobre el contenido contractual de este tipo de ventas, vulnerando la competencia estatal relativa a la legislación mercantil (art. 149.1.6 CE). Afrontará el TC, en primer lugar, el óbice procesal alegado por las partes que consideran que no se cumple en el presente caso el juicio de relevancia exigido por el art. 35.2 LOTC en lo que se refiere a la aplicabilidad del precepto cuestionado para la resolución del proceso a quo, dado que la sanción cuya procedencia se discute en dicho proceso no fue impuesta en aplicación del inciso final del art. 34.1 del Decreto Legislativo de la Generalitat de Cataluña 1/1993, sino por cometerse la infracción prevista en el art. 45 h) del referido Decreto Legislativo, que sanciona la práctica comercial de las rebajas incumpliendo los requisitos establecidos en la normativa vigente, al haber efectuado la sociedad mercantil sancionada ventas al público de productos a precios rebajados fuera de la temporada de reba- 
jas. Recordará el TC su doctrina acerca de la competencia prima facie para expresar el juicio de relevancia que es del Juez o Tribunal que la plantea de modo que el Tribunal Constitucional no puede adentrarse a sustituir o rectificar el criterio de los órganos judiciales proponentes, salvo en los supuestos en que de manera notoria, sin necesidad de examinar el fondo debatido y en aplicación de principios jurídicos básicos, se advierta que la argumentación judicial en relación con el juicio de relevancia carece de consistencia (entre otras, SSTC 17/1981, FJ 1; 106/1986, FJ 1; 142/1990, FJ 1; 189/1991, FJ 2; 174/1998, FJ 1; 63/2003, FJ 2; 51/2004, FJ 1; y 81/2009, FJ 3); de conformidad con esta doctrina debe entenderse cumplido a juicio del TC en el presente caso el juicio de relevancia: la norma cuestionada fue la expresamente aplicada por la Administración en el expediente que dio lugar al proceso judicial y que por ello y por su contenido material en relación con el caso no constata el TC en absoluto que no resulte en modo alguno aplicable al caso (por todas, SSTC 189/1991, FJ 2; 149/1994, FJ único y 168/2008, FJ 3); el juicio de aplicabilidad y relevancia se cumple en el Auto de planteamiento de la cuestión, puesto que se razona que el inciso cuestionado del art. 34.1 del Decreto Legislativo 1/1993, en cuanto integrante del concepto de venta en rebajas, es determinante para la definición de la infracción sancionada por la Administración catalana, infracción consistente en la práctica de dicha venta con el incumplimiento de los requisitos establecidos por la normativa vigente, y tipificada en el art. $45 \mathrm{~h}$ ) del Decreto Legislativo 1/1993, en el que la Administración catalana ha subsumido la conducta de la sociedad mercantil demandante en el proceso a quo; afrontará también el TC otra cuestión formal consistente en el alegato de la Letrada del Parlamento de Cataluña, que sostiene la aplicación de la doctrina del ius superveniens, por la modificación del Estatuto de Autonomía de Cataluña por la Ley Orgánica 6/2006 para determinar si el inciso cuestionado del art. 34.1 del Decreto Legislativo de la Generalitat de Cataluña 1/1993, de 9 de marzo, sobre comercio interior, se adecua al reparto de competencias constitucionalmente garantizado; en este sentido advertirá el Tc que la doctrina del ius superveniens, según la cual el control de las normas que incurren en un posible exceso competencial debe hacerse de acuerdo con las normas del bloque de la constitucionalidad vigentes al momento de dictar Sentencia [entre otras, SSTC 137/1986, FJ 4; 170/1989, FJ 3; 1/2003, FJ 9; 109/2003, FJ 6; 14/2004, FJ 8; 47/2004, FJ 7; y 135/2006, FJ 3 a)], no resulta aplicable a las cuestiones de inconstitucionalidad, como ya el TC ha precisado en di- 
versas ocasiones (SSTG 178/2004, FJ 5; 254/2004, FJ 5; y 164/2006, FJ 4), en consecuencia la cuestión a dilucidar se juzgará al amparo o de acuerdo con la norma estatutaria vigente en el momento en que fue planteada la cuestión en el proceso a quo, lo que conduce a tomar en consideración lo establecido en el Estatuto de Autonomía de Cataluña aprobado por Ley Orgánica 4/1979, careciendo de relevancia para la resolución de la presente cuestión la modificación estatutaria realizada por la Ley Orgánica 6/2006, en virtud de la cual el vigente Estatuto de Autonomía reconoce a la Generalitat competencia exclusiva en materia de comercio y ferias, en los términos establecidos en su art. 121, en relación con su art. 110, preceptos cuyas impugnaciones han sido objeto de la STC 31/2010, FFJJ 59 y 68 y fallo. A tenor de esta doctrina del TC para la resolución de la presente cuestión ha de tenerse en cuenta que el Decreto Legislativo de la Generalitat de Cataluña 1/1993, de 9 de marzo, sobre comercio interior, por el que se aprueba la refundición en un texto único de los preceptos de la Ley 1/1983, de 18 de febrero, y de la Ley 23/1991, de 29 de noviembre, de comercio interior, es una regulación dictada al amparo de la competencia que el art. 12.1.5 del Estatuto de Autonomía de Cataluña de 1979 reconocía a la Generalitat, en los términos de lo dispuesto en los arts. 38, 131, y 149.1.11 y $13 \mathrm{CE}$, en materia de comercio interior y defensa de los consumidores y usuarios, y sin perjuicio de la política general de precios y de la legislación sobre defensa de la competencia. Para afrontar el fondo de la cuestión trae el TC su doctrina expuesta en la STG 157/2004, en relación con un precepto de otra Ley autonómica (el inciso final del art. 46.1 de la Ley Foral 17/2001, de 12 de julio, reguladora del comercio en Navarra), que tenía prácticamente la misma redacción que el inciso aquí cuestionado, y que fue declarado inconstitucional y nulo por la citada STC 157/2004, al entender el TC que esa regulación invadió la competencia exclusiva del Estado en materia de legislación mercantil (art. 149.1.6 CE). El art. 34.1 del Decreto Legislativo de la Generalitat de Cataluña 1/1993, de 9 de marzo, sobre comercio interior, establece que $[s]$ e consideran ventas a precio rebajado las ventas en las que se ofrece al público, mediante cualquier tipo de publicidad, una reducción de los precios o unas condiciones especiales de estos que supongan su aminoración en relación con los precios practicados habitualmente, siendo este inciso final (o unas condiciones especiales de estos que supongan su aminoración en relación con los precios practicados habitualmente) el que el órgano judicial promotor de la cuestión cuestiona, atendiendo a la doctrina sentada en la citada STC 157/2004, por entender que 
puede incurrir en infracción de lo dispuesto en el art. 149.1.6 CE, que atribuye competencia exclusiva al Estado en materia de legislación mercantil, y del art. 24.1 de la Ley 7/1996, de 15 de enero, de ordenación del comercio minorista, que establece que [s]e entiende que existe venta en rebajas cuando los artículos objeto de la misma se ofertan, en el mismo establecimiento en el que se ejerce habitualmente la actividad comercial, a un precio inferior al fijado antes de dicha venta; recordará el TC que en su Sentencia 157/2004 se reitera que la determinación de las relaciones contractuales propias de los diferentes tipos de ventas desarrolladas por los comerciantes se inscribe en el ámbito del art. 149.1.6 CE (FJ 11), concluyéndose (en ese mismo FJ) que es obvio que el art. 46.1 de la Ley Foral 17/2001 se ha introducido en el núcleo normativo que es propio de la figura contractual de la venta en rebajas, separándose, además, de la conceptualización que de este contrato ha realizado la Ley estatal 7/1996 en su art. 24.1. En efecto, definir la venta en rebajas como aquella modalidad de venta en la que se ofertan al público artículos 'a un precio inferior al fijado antes de su venta o en unas condiciones que supongan una minoración en relación con el precio practicado habitualmente' supone regular las relaciones contractuales en un aspecto tan central como es el precio de los productos que se someten a esta modalidad de venta. $Y$ hemos de coincidir con el Abogado del Estado en que la incidencia sobre dicha relación contractual desborda el marco fijado al respecto por la legislación estatal, puesto que la norma foral no sólo incluye como venta en rebajas la de aquellos productos que se ofertan a 'un precio inferior al fijado antes de su venta', sino también la de los que se ofertan 'en unas condiciones que supongan una minoración en relación con el precio practicado habitualmente'. Es claro que la 'minoración' en el precio no es asimilable, en términos conceptuales y en el preciso y estricto significado propio de esta expresión, a la oferta de condiciones complementarias que supongan, de hecho, una minoración en aquél, por lo que la regulación autonómica va más allá de lo previsto en la estatal, incidiendo en el ámbito del contenido contractual de la operación que contempla y, con ello, entrando en campo propio de la 'legislación mercantil', competencia exclusiva del Estado a tenor de lo establecido en el art. 149.1.6 CE. En definitiva, el inciso 'o en unas condiciones que supongan una minoración en relación con el precio practicado habitualmente' del art. 46.1 de la Ley Foral 17/2001 es inconstitucional y nulo. Concluirá el TC considerando que la aplicación al presente caso de la doctrina sentada en la STC 157/2004 ha de conducir a la estimación de la cuestión de inconstitucionalidad planteada por la Sección Quinta de la Sala de lo Contencioso-Administrativo del Tribunal Superior de Justicia de Cataluña, declarando, en consecuencia, la inconstitucionalidad y nulidad del inciso o unas condiciones especiales de estos que supongan su aminoración en relación con los precios practicados habitualmente" del art. 34.1 del 
Decreto Legislativo controvertido al considerar que éste incide en el núcleo normativo propio de la figura contractual de la venta en rebajas, desbordando el marco fijado al respecto por el art. 24.1 de la Ley estatal 7/1996, de ordenación del comercio minorista, puesto que la norma catalana incluye como venta en rebajas también la de aquellos productos que se ofertan en unas condiciones especiales de los precios que supongan su aminoración en relación con los precios practicados habitualmente, de modo que la regulación cuestionada provoca la alteración de una modalidad de contrato mercantil contenida en la legislación estatal, vulnerando con ello la competencia exclusiva del Estado en materia de legislación mercantil (art. 149.1.6 CE).

\section{Sentencia 30/2011, de 16 de marzo (BOE de 11 de abril). Ponen- te: Delgado Barrio (Recurso de inconstitucionalidad).}

Preceptos constitucionales: 147.2.d), 149.1.22, 149.3. otros:

Objeto: Arts. 43, 50.1 a), 50.2 y 51 de la Ley Orgánica 2/2007, de 19 de marzo, de reforma del Estatuto de Autonomía para Andalucía

Materias: Competencias estatales y autonómicas. Concepto de cuenca intercomunitaria; determinación de la competencia estatal de éstas.

El presente recurso de inconstitucionalidad tiene por objeto principal el art. 51 de la Ley Orgánica 2/2007, de 19 de marzo, de reforma del Estatuto de Autonomía para Andalucía (EAAnd), impugnado por razón de las competencias que en el mismo se atribuyen a la Comunidad Autónoma de Andalucía sobre la cuenca hidrográfica del Guadalquivir, con infracción, a juicio del Consejo de Gobierno de la Junta de Extremadura, de las reservadas al Estado en el art. 149.1.22 CE. También son objeto de impugnación formal los arts. 43, 50.1 a) y 50.2 aunque tales preceptos se recurren en la medida en que su interpretación sistemática en relación con el art. 51 EAAnd padecería, por derivación, del mismo defecto de inconstitucionalidad que en él se denuncia. La constitucionalidad que se cuestiona se basa esencialmente en que tratándose de una cuenca hidrográfica supracomunitaria, la Comunidad Autónoma de Andalucía no puede asumir en su Estatuto la competencia exclusiva sobre las aguas de la cuenca del Guadalquivir que transcurran por su territorio, pues ello pugnaría con el art. 
149.1.22 CE, que reserva al Estado competencias delimitadas con arreglo a un criterio territorial que, en virtud de la legislación estatal de aguas, se concreta, con el beneplácito de la jurisprudencia constitucional, en el criterio de la cuenca hidrográfica natural como unidad de gestión en el ámbito de la política hidráulica. $\mathrm{Al}$ atribuir a la Comunidad Autónoma competencias constitucionalmente reservadas al Estado, el precepto impugnado también lesionaría el art. 147.2 d) CE, que contempla que los Estatutos de Autonomía deberán contener las competencias asumidas dentro del marco establecido en la Constitución. La representación del Estado propone una interpretación del precepto impugnado conforme con la Constitución, en el sentido de entender que con él no se atribuye a la Comunidad Autónoma andaluza la competencia exclusiva sobre las aguas de la cuenca del Guadalquivir que transcurren por su territorio, sino que únicamente se proclama que la Comunidad Autónoma ostenta una serie de competencias exclusivas sobre tales aguas, esto es, sólo determinadas competencias (aun con el carácter de exclusivas), pero no todas las competencias posibles, sino respetando las que, también con carácter exclusivo, el art. 149.1.22 CE reserva al Estado. La falta de legitimación activa del Gobierno recurrente es esgrimida por el Parlamento y la Junta de Andalucía, defendiendo la constitucionalidad sin reservas del art. 51 EAAnd, alegando que el legislador estatutario puede modificar la configuración del Derecho de aguas siempre que respete los principios que se tratan de salvaguardar mediante el sistema de gestión indivisible de los recursos pertenecientes a una misma cuenca hidrográfica, lo que en opinión de ambos se garantiza sobradamente con todas las salvedades y condiciones contempladas en el propio art. 51 EAAnd. Comienza el TC por analizar la cuestión procesal suscitada en relación con la legitimación necesaria para interponer el presente recurso de inconstitucionalidad; ésta se justifica a partir de una doble constatación: de un lado, el carácter supracomunitario de la cuenca hidrográfica del Guadalquivir, cuyo ámbito territorial comprende dieciocho términos municipales de la provincia de Badajoz; y de otro, el perjuicio causado con las normas recurridas a la propia autonomía de la Comunidad Autónoma de Extremadura; estas dos circunstancias serían fundamento suficiente, a juicio de los recurrentes, para reconocerle la legitimación necesaria para interponer este recurso, incluso partiendo de la interpretación más restrictiva posible del art. 32 de la Ley Orgánica del Tribunal Constitucional (LOTG); a este argumento se oponen el Parlamento, así como la Junta de Andalucía en el entendimiento de que ni siquiera desde la interpretación más flexible del art. 32 LOTG es posible re- 
conocer al Gobierno de la Junta de Extremadura la legitimación necesaria para impugnar la Ley Orgánica 2/2007; de una parte, porque el Gobierno demandante no habría fundamentado debidamente la existencia de una lesión concreta y efectiva de sus propias competencias; y, de otra, porque el tenor de los preceptos recurridos excluye toda posible afectación del ámbito de autonomía de otras Comunidades Autónomas; sería el argumento central que el recurrente lo es en defensa de las competencias del Estado ex art. 149.1.22 CE, de suerte que con su demanda perseguiría la depuración objetiva del ordenamiento con abstracción de cualquier conexión con un interés autonómico propio, lo que estaría muy lejos del sentido más cabal del art. 32.2 LOTC, cuya flexibilización jurisprudencial no ha llegado al extremo de confundirlo con el del art. 32.1 LOTC. El TC estima que esta objeción no puede prosperar; trae en su apoyo el TC su doctrina sobre el art. 32.2 LOTC: la esfera de interés de la Comunidad Autónoma que justifica su legitimación no se identifica con la defensa de sus competencias (SSTC 84/1982, 26/1987 y 74/1987), pues ni el recurso de inconstitucionalidad puede ser equiparado al conflicto de competencias, siendo como es un instrumento al servicio de la depuración objetiva del ordenamiento, ni cabe identificar el "propio ámbito de autonomía' del art. 32.2 LOTC con el elenco de competencias estatutarias", habiendo concluido que "dicha expresión legal remite, más ampliamente, a la posición institucional que en el ordenamiento ostentan las Comunidades Autónomas, es decir, al conjunto de sus competencias y facultades y también a las garantías, constitucionales y estatutarias, que preservan dicha autonomía (STC 56/1990, fundamento jurídico 3)" (STC 28/1991 FJ 3); asimismo en atención a la STC 48/2003 o los argumentos reiterados en la STC 247/2007, FJ 2 a), si bien en un principio este Tribunal interpretó la restricción del art. 32.2 LOTG en un sentido estrictamente competencial (así, STG 25/1981, de 14 de julio),... muy pronto -ya con la STC 84/1982, de 23 de diciembre- se inició una línea jurisprudencial de progresiva flexibilización de ese criterio, hasta el extremo de que puede afirmarse que los condicionamientos materiales a la legitimación de las Comunidades Autónomas para impugnar leyes del Estado constituyen una verdadera excepción; ya se dijo en la STC 199/1987, que la legitimación de las Comunidades Autónomas para interponer el recurso de inconstitucionalidad no está al servicio de una competencia violada, sino de la depuración del ordenamiento jurídico $y$, en este sentido,... se extiende a todos aquellos supuestos en que exista un punto de conexión material entre la ley estatal y el ámbito competencial autonómico, lo cual, a su vez, no puede ser interpretado restrictivamente' (FF 1)" (STC 48/2003, FJ 1); a este interés objetivo se suma el interés institucional de los recurrentes en la defensa de su ámbito de autonomía; 
esa sola circunstancia ya es sobradamente acreditativa de la existencia de una conexión material relevante entre el Estatuto impugnado y el ámbito competencial de la Comunidad Autónoma de Extremadura, lo que resulta suficiente per se para reconocer al Consejo de Gobierno de la Junta de Extremadura la legitimación institucional prevista en el art. 162.1 a) CE. La competencia sólo podrá ostentarla el Estado, como bien se deriva de la demanda de los recurrentes, éstos no recurren sino en defensa de un orden de distribución de competencias que somete las aguas de la cuenca a la que pertenecen dieciocho municipios extremeños a la competencia exclusiva del Estado central. Al TC no le parece discutible el legítimo interés de la Comunidad Autónoma de Extremadura en que, de no poder ser ella misma la competente para la entera disciplina del régimen de aquellas aguas, no lo sea la Comunidad Autónoma de Andalucía, sino únicamente el Estado central y, en la medida en que así resulte del criterio territorial adoptado por el legislador de aguas, la propia Comunidad Autónoma extremeña en el margen que para el ejercicio de competencias autonómicas permita el ejercicio de las que primeramente correspondan al Estado; será criterio del TC que procede descartar la concurrencia del óbice procesal aducido. En relación con la cuestión de fondo planteada en este proceso constitucional considera el TC que es necesario tener presentes dos consideraciones, atinentes al alcance y al contenido de nuestro enjuiciamiento. En primer lugar, el problema de la constitucionalidad del art. 51 EAAnd remite a si dicha competencia se encuentra o no reservada al Estado por el art. 149.1.22 CE, puesto que sólo en caso de respuesta negativa podría ésta, en los términos del art. $149.3 \mathrm{CE}, c^{-}$ rresponder a las Comunidades Autónomas, de acuerdo con sus respectivos Estatutos, de tal manera que, en atención al objeto de la impugnación, queda, por tanto, excluida del ámbito de nuestro enjuiciamiento la cuestión de la licitud o ilicitud constitucional y de los límites de una eventual atribución extraestatutaria de las competencias a las que se refiere el art. 51 EAAnd; en segundo lugar, el precepto impugnado debe enjuiciarse desde una doble perspectiva: mediante la comprobación de si el art. 51 EAAnd vulnera el art. 149.1.22 CE por razones materiales o sustantivas; al tiempo que esa comprobación ha de extenderse a averiguar si esa regulación resulta constitucionalmente viable a través del tipo de ley que la contiene, de tal manera que si la respuesta fuera negativa el precepto impugnado incurriría en una inconstitucionalidad de carácter formal, en la medida en que esta consideración traería causa de la invalidez del tipo normativo empleado en punto a la formalización jurídica de la decisión que se impugna. Será criterio 
del TC que el examen sobre la posible inconstitucionalidad del art. 51 EAAnd por razones materiales debe preceder al control de la constitucionalidad formal del referido precepto dado que la cuestión debatida afecta a la competencia exclusiva del Estado ex art. 149.1.22 CE, que recae sobre un recurso natural de tan esencial importancia vital, social y económica como es el agua; recordará el TC su doctrina al respecto: la Constitución, que si fija las materias de competencia estatal, no especifica directamente el contenido o alcance ni de las materias ni de las funciones materiales sobre las que se proyecta aquélla, ni tampoco contiene reglas expresas de interpretación que inmediatamente permitan concretar dicho contenido o alcance, lo que, en última instancia, sólo corresponde precisar a este Tribunal Constitucional en el ejercicio de su jurisdicción (STC 247/2007, FJ 7) y asimismo que el Estatuto de Autonomía, en cuanto que es norma estatal, puede realizar su función atributiva de competencias a la Comunidad Autónoma, con la consiguiente delimitación entre las competencias estatales y autonómicas, incidiendo en el alcance de las primeras, si bien es obvio que esa posible regulación normativa estatutaria no puede en ningún caso quebrantar el marco del art. 149.1 CE, desnaturalizando el contenido que sea propio de cada materia y que permite su recognoscibilidad como institución. Lo importante, en este sentido, es que el Estatuto de Autonomía, por ser norma de eficacia territorial limitada, si en ocasiones hubiere de realizar alguna precisión sobre el alcance de las materias de competencia estatal, lo haga para favorecer la mayor concreción de las competencias autonómicas que se correlacionan con ella y que, al hacerlo, no impida el despliegue completo de las funciones propias de la competencia estatal regulada en el art. 149.1 CE de que se trate. Sólo si se satisfacen estas exigencias, tal modo de proceder resultará acorde a la Constitución..., en cualquier caso, sólo a este Tribunal corresponde apreciar, como intérprete supremo de la Constitución, si los Estatutos de Autonomía han incurrido en algún vicio de inconstitucionalidad, sea por excederse en el margen interpretativo de la Constitución en el que legítimamente pueden intervenir, sea por cualquier otro motivo" (STC 247/2007, FJ 10); en consecuencia, sostiene el TC, resulta inexcusable que se pronuncie sobre el contenido y alcance de la competencia exclusiva estatal en materia de aguas establecida en el art. 149.1.22 CE y la incidencia que la asunción de competencias autonómicas que se contiene en el art. 51 EAAnd tiene en el alcance de la referida competencia estatal. Desde estas posiciones, procede examinar si el art. 51 EAAnd vulnera el art. 149.1.22 CE por razones materiales o sustantivas; atendiendo al contenido de la regulación que incorpora, para lo cual resulta obligado partir de la doctrina sentada en la STC 227/1988, (reiterada en las SSTC 161/1996 y 118/1998), en la que el TC se pronunció sobre la constitucionalidad del principio de unidad de gestión de cuenca hidrográfica, como criterio de delimita- 
ción territorial utilizado por la Ley 29/1985 para precisar el alcance del art. 149.1.22 GE, criterio que se mantiene en la vigente Ley de aguas (texto refundido aprobado por Real Decreto Legislativo 1/2001, de 20 de julio, reformado por la Ley 62/2003, de 30 de diciembre), que define la cuenca hidrográfica, en coincidencia con lo establecido por el art. 2 de la Directiva 2000/60/CE de 23 de octubre de 2000, del Parlamento Europeo y del Consejo, por la que se establece un marco comunitario de actuación en el ámbito de la política de aguas (modificada por la Directiva 2008/32/CE de 11 de marzo de 2008, del Parlamento Europeo y del Consejo), como la superficie de terreno cuya escorrentía superficial fluye en su totalidad a través de una serie de corrientes, ríos y, eventualmente, lagos, hacia el mar por una única desembocadura, estuario o delta. Por ello, las aguas continentales superficiales, así como las corrientes de aguas subterráneas renovables, en la medida en que confluyen en la red de cauces naturales de una cuenca hidrográfica, pertenecen a dicha cuenca y se integran todas ellas, a través de la misma, en el ciclo hidrológico (art. 1.3 de la Ley de aguas). Por otra parte, al concepto de cuenca hidrográfica ha de añadirse el de demarcación $h i^{-}$ drográfica, entendiéndose por tal la zona terrestre y marina compuesta por una o varias cuencas hidrográficas vecinas y las aguas de transición, subterráneas y costeras asociadas a dichas cuencas (art. 16 bis de la Ley de aguas, añadido por la Ley 62/2003, de 30 de diciembre, y que incorpora asimismo la definición contenida en el art. 2 de la Directiva 2000/60/CE); considerará el TC que al atribuir a la Comunidad Autónoma de Andalucía competencias exclusivas sobre aguas de la cuenca del Guadalquivir, siendo como es ésta una cuenca hidrográfica intercomunitaria, el art. 51 EAAnd se separa de la previsión establecida en el art. 149.1.22 CE y del criterio que utiliza la Ley de aguas para la concreción de la delimitación territorial de las competencias del Estado que figura en el citado precepto constitucional (aguas [que] discurran por más de una Comunidad Autónoma). Y lo hace el precepto estatutario con un criterio (aguas de la cuenca del Guadalquivir que transcurren por su territorio y no afectan a otra Comunidad Autónoma) que conduce a un entendimiento que acoge un modelo de gestión fragmentada de las aguas pertenecientes a una misma cuenca hidrográfica intercomunitaria, conforme al cual una parte de las aguas de la cuenca del Guadalquivir sería de competencia exclusiva de la Comunidad Autónoma andaluza y otra parte de las aguas de esa misma cuenca intercomunitaria sería de competencia exclusiva del Estado; acudirá el TC, a estos efectos, a su doctrina en la STC $227 / 1988$, de 29 de noviembre, en la que se hicieron unas consideraciones que interesa aquí recordar: (a) En primer lugar, es necesario par- 
tir, ante todo, de las especificas referencias constitucionales a la materia 'aguas' que se contienen en los arts. 148.1 .10 y 149.1.22 de la Constitución. Según el primero de estos preceptos, las Comunidades Autónomas pueden asumir competencias sobre 'los proyectos, construcción y explotación de los aprovechamientos hidráulicos, canales y regadíos de interés de la Comunidad Autónoma' respectiva; de conformidad con el segundo, el Estado tiene competencia exclusiva sobre 'la legislación, ordenación y concesión de recursos y aprovechamientos hidráulicos cuando las aguas discurran por más de una Comunidad Autónoma'. Ambos preceptos no son coincidentes, ni desde el punto de vista de la materia que definen, ni en atención al criterio que utilizan para deslindar las competencias estatales y autonómicas sobre la misma, que, en el primer caso, es el interés de la Comunidad Autónoma, y en el segundo, el territorio por el que las aguas discurren (FJ 13); (b) en segundo término, en la STC 227/1988, rechazó el TC que fuera inconstitucional que la Ley de aguas utilice como criterio territorial para el ejercicio de las competencias del Estado en materia de aguas continentales el de la cuenca hidrográfica que exceda de una Comunidad Autónoma, puesto que, cuando la Constitución utiliza la expresión 'aguas que discurran', no toma en consideración necesariamente las corrientes o cursos aislados, ni menos aún obliga a compartimentar las competencias sobre los diferentes tramos de un mismo curso fluvial. Antes bien, es lícito y razonable entender, como asi lo hace la Ley impugnada, que, para delimitar las competencias exclusivas del Estado, la norma constitucional permite referirse al conjunto integrado de las aguas de cada cuenca que, a través de corrientes principales y subalternas, trasvasan los confines del territorio de una Comunidad Autónoma. A ello no se opone el hecho de que la Constitución y los Estatutos de Autonomía no hayan sancionado explíitamente el concepto estructural de la cuenca hidrográfica, pues en ningún caso podría atribuirse a esta omisión el sentido de que sus redactores lo han querido excluir implícitamente, lo que no se desprende, antes al contrario, de los antecedentes parlamentarios (FJ 15); (c) en tercer lugar, aunque es cierto que en la STC 227/1988 no deja de señalarse que del conjunto de las normas del bloque de la constitucionalidad aplicables en materia de aguas puede extraerse más de una interpretación, sin forzar los conceptos empleados por tales normas y dentro siempre de los límites constitucionales", no lo es menos que asimismo se advierte inmediatamente que en el desempeño de la tarea interpretativa de las normas competenciales establecidas en la Constitución y en los Estatutos de Autonomía, y por imperativo del criterio de unidad de la Constitución, que exige dotar de la mayor fuerza normativa a cada uno de sus preceptos, este Tribunal ha de tener en cuenta también el conjunto de los principios constitucionales de orden material que atañen, directa o indirectamente, a la ordenación y gestión de recursos naturales de tanta importancia como son los recursos hidráulicos, principios que, a modo de sintesis, se condensan en el mandato constitucional que obliga a todos los poderes públicos a velar por la 'utilización racional de todos los recursos naturales' 
(art. 45.2 de la Constitución). Por ello, entre las diversas interpretaciones posibles de las reglas de distribución de competencias, este Tribunal sólo puede respaldar aquellas que razonablemente permitan cumplir dicho mandato y alcanzar los objetivos de protección y mejora de la calidad de vida y defensa y restauración del medio ambiente a los que aquél está inseparablemente vinculado" (FJ 13); (d) como corolario de lo anterior, en la citada STG 227/1988, ya se realizó una precisión que ahora se revela de la máxima importancia, al afirmar que la expresión 'aguas que discurran por más de una Comunidad Autónoma' es un concepto constitucional cuyo significado debe desentrañarse atendiendo a criterios lógicos, técnicos y de experiencia. Desde el punto de vista de la lógica de la gestión administrativa, no parece lo más razonable compartimentar el régimen jurídico y la administración de las aguas de cada curso fluvial y sus afluentes en atención a los confines geográficos de cada Comunidad Autónoma, pues es evidente que los usos y aprovechamientos que se realicen en el territorio de una de ellas condicionan las posibilidades de utilización de los caudales de los mismos cauces, principales y accesorios, cuando atraviesan el de otras Comunidades o surten a los cursos fluviales intercomunitarios. Este condicionamiento, por lo demás, no sólo se produce aguas arriba en perjuicio de los territorios por los que una corriente desemboca en el mar, sino también aguas abajo, en posible perjuicio de los territorios donde nace o por donde transcurre, ya que la concesión de caudales implica en todo caso el respeto a los derechos preexistentes, de manera que los aprovechamientos concedidos en el tramo inferior o final de un curso pueden impedir o menoscabar las facultades de utilización de las aguas en tramos superiores. Por el contrario, el criterio de la cuenca hidrográfica como unidad de gestión permite una administración equilibrada de los recursos hidráulicos que la integran, en atención al conjunto de intereses afectados que, cuando la cuenca se extiende al territorio de más de una Comunidad Autónoma, son manifiestamente supracomunitarios. Desde un punto de vista técnico, es claro también que las aguas de una misma cuenca forman un conjunto integrado que debe ser gestionado de forma homogénea... Así lo pone de manifiesto la experiencia internacional sobre la materia... La experiencia de gestión de estos recursos en nuestro pais, articulada en torno a la unidad de cada cuenca, desde que se adoptó una concepción global de la política hidráulica, conduce a la misma conclusión (FJ 15); (e) como consecuencia de lo anterior, en la STC 227/1988, FJ 15, no se acogió el entendimiento fragmentador de la cuenca hidrográfica que propugnaba el Gobierno Vasco en su impugnación de la Ley 29/1985 de aguas, ley refundida en la vigente Ley de aguas (texto refundido aprobado por Real Decreto Legislativo 1/2001), al pretender introducir el concepto de curso fluvial concreto para reclamar la competencia autonómica sobre los cursos fluviales o corrientes de agua que discurran integramente por el territorio de una Comunidad Autónoma, ya desemboquen integramente en otro curso fluvial, en un lago o en el mar, e incluso el concepto de tramo 
final, por referencia a los cursos fluviales que discurran por más de una Comunidad Autónoma, en el sentido de que aquélla donde muera cada curso tendría competencia sobre el tramo final, desde que entra en su territorio, pues en tal caso la utilización que se haga del caudal sólo afecta a los intereses de esa Comunidad Autónoma; (f) asimismo, en la STC 227/1988, FJ 16, se advirtió que los flujos o corrientes de aguas subterráneas, en la medida en que convergen en la red de cauces de una cuenca hidrográfica... pertenecen a dicha cuenca y se integran así, a través de la misma, en el ciclo hidrológico; por ello, una vez admitida la constitucionalidad del criterio de la cuenca hidrográfica, de conformidad con lo dispuesto en el art. 149.1.22 de la Constitución, no es dudoso que el mismo criterio territorial de delimitación de competencias puede aplicarse a las aguas subterráneas, siempre que se trate de aguas renovables integradas en la red de cauces confluyentes en una misma cuenca, y en tal sentido deben interpretarse las referencias a las aguas subterráneas que se contienen en los Estatutos de Autonomía. En suma considerará el TC que su punto de partida ha de ser necesariamente el integrado por las consideraciones fundamentales de la STC 227/1988, ratificada por las SSTC 161/1996 y 11/1998 que ahora le llevan a concluir que aunque el criterio de la cuenca hidrográfica no sea el único constitucionalmente viable en el marco del art. 149.1.22 CE, sí ha de declararse que no le es dado al legislador estatal concretar las competencias del Estado en esta materia mediante una fragmentación de la gestión de las aguas intercomunitarias de cada curso fluvial y sus afluentes. Como ya se señaló en la citada STC 227/1988, una interpretación sistemática del art. 149.1.22 CE, en su relación con el art. 45.2 CE que reclama una utilización racional de los recursos naturales, llevó al TC a sostener que entre las diversas interpretaciones posibles de las reglas de distribución de competencias este Tribunal sólo puede respaldar aquellas que razonablemente permitan cumplir dicho mandato, añadiendo que no parece lo más razonable compartimentar el régimen jurídico y la administración de las aguas de cada curso fluvialy sus afluentes en atención a los confines geográficos de cada Comunidad Autónoma pues es evidente que los usos y aprovechamientos que se realicen en el territorio de una de ellas condicionan las posibilidades de utilización de los caudales de los mismos cauces, principales y accesorios, cuando atraviesan el de otras Comunidades o surten a los cursos fluviales intercomunitarios, en tanto que por el contrario, el criterio de la cuenca hidrográfica como unidad de gestión permite una administración equilibrada de los recursos hidráulicos que la integran, en atención al conjunto de intereses afectados que, cuando la cuenca se extiende al territorio de más de una Comunidad Autónoma, son manifiestamente supracomunitarios, de modo que es claro también que las aguas de una misma cuenca forman un conjunto integrado que debe ser gestionado de forma homogénea (STC 227/1988, FJ 15). En definitiva, concluirá el TC que 
el conjunto de esos intereses manifiestamente supracomunitarios, debe ser gestionado de forma homogénea, lo que excluye la viabilidad constitucional de la compartimentación del régimen jurídico y la administración de las aguas de cada curso fluvial y sus afluentes en atención a los confines geográficos de cada $\mathrm{Co}^{-}$ munidad Autónoma" (STC 227/1988, FJ 15). En atención a lo expuesto concluirá el TG que el art. 51 EAAnd debe reputarse inconstitucional y nulo porque, al compartimentar el régimen jurídico y la administración de las aguas pertenecientes a una misma cuenca hidrográfica supracomunitaria, como es la del Guadalquivir, el citado precepto vulnera el art. 149.1.22 CE. Esta consideración sobre la inconstitucionalidad de carácter sustantivo en que incurre el precepto estatutario impugnado podría ser ya suficiente para fundar la estimación del recurso y la consiguiente declaración de inconstitucionalidad y nulidad del art. 51 EAAnd. Sin embargo, la singular posición que corresponde al Estatuto de Autonomía en la configuración del Estado autonómico (SSTC 247/2007, FJ 5, y 31/2010,, FJ 4), así como la esencial importancia vital, social y económica del agua (STC 227/1988, FFJJ 6 y 20), recurso natural que constituye el objeto del art. 149.1.22 CE, justifican y aún aconsejan al TC extender su enjuiciamiento al análisis de la constitucionalidad formal de la disposición estatutaria controvertida, dando con ello expresa respuesta a la tacha de inconstitucionalidad esgrimida en tal sentido por el Gobierno autonómico recurrente. El objeto de debate en relación con esta segunda cuestión planteada se contrae estrictamente a dilucidar la legitimidad constitucional de que la concreción del concepto del art. 149.1.22 CE aguas [que] discurran por más de una Comunidad Autónoma" se lleve a cabo en un Estatuto de Autonomía; se trata de averiguar la aptitud formal de un Estatuto de Autonomía, en cuanto tipo normativo para concretar respecto de una determinada Comunidad Autónoma el criterio territorial empleado por el art. 149.1.22 CE apartándose de lo que éste establece y de lo prescrito por el legislador estatal competente en materia de aguas mediante el art. 16 de la Ley de aguas: las partes, obviamente han dado una respuesta diversa a la cuestión; recordará el TC lo ya señalado: que el art. 51 EAAnd, al atribuir a la Comunidad Autónoma de Andalucía competencias exclusivas sobre las aguas de la cuenca del Guadalquivir, siendo como es ésta una cuenca hidrográfica intercomunitaria, se separa del criterio empleado por la Ley de aguas en punto a la concreción del criterio territorial empleado por el art. 149.1.22 CE; por lo que se refiere a las relaciones entre las normas estatutarias y la delimitación de las competencias del Estado ex art. 149.1 CE, partirá el TC de si las primeras contribuye[n] a perfilar... el ámbito de normación y 
poder propio del Estado ello es sólo en la medida en que las competencias del Estado dependen mediatamente en su contenido y alcance de la existencia y extensión de las competencias asumidas por las Comunidades Autónomas en el marco extraordinariamente flexible representado por el límite inferior o mínimo del art. $148 \mathrm{CE}$ y el máximo o superior, a contrario, del art. 149 CE. Esto no hace del Estatuto, sin embargo, una norma atributiva de las competencias del Estado (STC 31/2010, FJ 5). El Estatuto de Autonomía tampoco es norma de ejercicio de las competencias estatales previstas por el art. 149.1 CE, de modo que, en caso de hacer alguna precisión sobre el alcance de éstas, su constitucionalidad pasa por el respeto de dos límites: el primero, de carácter positivo, consiste en que dicha precisión se haga para favorecer la mayor concreción de las competencias autonómicas que se correlacionan con las competencias estatales que puedan presentar problemas de delimitación; y el segundo, de carácter negativo, reside en que la precisión estatutaria "no impida el despliegue completo de las funciones propias de la competencia estatal regulada en el art. 149.1 CE de que se trate. Sólo si se satisfacen estas exigencias, tal modo de proceder resultará acorde a la Constitución" (STC 247/2007, FJ 10). Según el TC en el presente caso es evidente que con la definición estatutaria del criterio territorial determinante de la delimitación de las competencias atribuidas al Estado por el art. 149.1.22 CE no sólo se están asumiendo competencias fuera del ámbito que se acaba de señalar -arts. 148 y $149 \mathrm{CE}$ a sensu contrario- sino que además se menoscaban gravemente las funciones propias de las competencias estatales, cuya razón de ser no es otra, en la lógica del sistema de descentralización característico del Estado autonómico, que la garantía de la unidad última del ordenamiento a partir de un mínimo denominador común normativo, imprescindible en tanto que presupuesto para que la diversificación inherente al principio autonómico no se resuelva en contradicciones de principio con el fundamento unitario del Estado. Tal función integradora padecería de manera irremisible si los Estatutos de Autonomía fueran constitucionalmente capaces de imponer un criterio de delimitación competencial respecto de potestades y funciones que, como es el caso con las aguas que discurren por varias Comunidades Autónomas, han de proyectarse sobre una realidad física supracomunitaria, cuya disciplina sería sencillamente imposible si los criterios adoptados en los Estatutos de las Comunidades Autónomas interesadas resultaran incompatibles o excluyentes; según el TC éste sería el caso del art. 51 controvertido. $\mathrm{El}$ art. 51 EAAnd no supera, en suma, el canon de constitucionalidad expuesto y vulnera el art. 149.1.22 CE por razón de la inadecuación formal del Estatuto de Autonomía para realizar una concreción del criterio territorial de delimitación de las competencias que el citado 
precepto constitucional reserva al Estado. Tampoco aceptará el TC la solución de la admisibilidad de la interpretación conforme que requiere que la interpretación compatible con la Constitución sea efectivamente deducible de la disposición impugnada, sin que corresponda al TC la reconstrucción de una norma contra su sentido evidente y, por ende, la creación de una norma nueva para concluir que esa reconstrucción es la norma constitucional, con la consiguiente asunción por el TC de una función de legislador positivo que institucionalmente no le corresponde (SSTC 11/1981, FJ 4; 45/1989, FJ 11; 96/1996, FJ 22; 235/1999, FJ 13; 194/2000, FJ 4; 184/2003, FJ 7 y 235/2007, FJ 7, entre otras muchas), en definitiva la interpretación de conformidad defendida por el Abogado del Estado no satisface los presupuestos señalados en la doctrina del TC. En definitiva, dada la inequívoca inconstitucionalidad material y formal del art. 51 EAAnd, no puede aceptarse la propuesta de interpretación conforme a la Constitución sugerida por el Abogado del Estado, de modo que el referido precepto estatutario debe declararse contrario al art. 149.1.22 CE y, por tanto, inconstitucional y nulo, dado que establece un criterio fragmentador de la gestión de una cuenca hidrográfica intercomunitaria para asumir competencias que corresponden al Estado, a lo que se une la inadecuación formal del Estatuto de Autonomía para la concreción del criterio territorial de delimitación de las competencias reservadas al Estado por dicho precepto constitucional. El recurso de inconstitucionalidad se dirige asimismo contra el art. 43 EAAnd, referido a la disciplina general del alcance territorial y los efectos de las competencias de la Comunidad Autónoma de Andalucía; no obstante entiende el TC que la impugnación de este precepto se fundamenta en la relación que la Junta de Extremadura cree advertir entre aquella disciplina común y el caso particular del alcance territorial de la competencia asumida en el art. 51 EAAnd; apreciada la inconstitucionalidad de este último precepto, el régimen general del art. 43 EAAnd nunca podría particularizarse en los términos que pudieran resultar de la vigencia del art. 51 EAAnd. Tampoco puede prosperar la impugnación del art. 50.1 a) EAAnd, recurrido con el argumento de que, al no especificar que las competencias allí referidas se proyectan sobre las aguas que "únicamente" transcurran por territorio andaluz, incurre en una ambigüedad buscada a propósito para dar cabida a interpretaciones antagónicas y, por tanto, contrarias al principio de seguridad jurídica; resulta evidente para el TC, que la declaración de inconstitucionalidad y nulidad del art. 51 EAAnd, en tanto que excepción del art. 50 EAAnd, supone la pervivencia de este último como norma que 
no admite ni permite otro criterio territorial que el de las aguas que transcurran íntegramente por Andalucía. Por último, y en relación con el art. 50.2 EAAnd, afirma el Consejo de Gobierno extremeño que sus dudas de constitucionalidad se centran en el último inciso del precepto, en cuanto atribuye a la Comunidad Autónoma de Andalucía facultades de policía del dominio público hidráulico sin dejar claro el tipo de cuencas al que se está haciendo referencia; considerará el TC que si se tratara de las intercomunitarias, sería constitucionalmente improcedente que el Estatuto asumiera así una competencia que corresponde al Estado (STC 161/1996); así es, en efecto, y tal es la razón por la que, declarada la inconstitucionalidad del art. 51 EAAnd, esa interpretación no puede caber en el art. 50.2 EAAnd. Todo ello sin perjuicio de que, como alega el Abogado del Estado, nada impide que la legislación estatal de aguas confiera a las Comunidades Autónomas funciones o facultades de policía del dominio público hidráulico en cuencas intercomunitarias (STC 161/1996), o que, según el art. 17 d) de la Ley de aguas, entre las funciones del Estado en relación con el dominio público hidráulico se encuentre el otorgamiento de autorizaciones cuya tramitación puede encomendarse a las Comunidades Autónomas. El TC estima parcialmente el recurso y declara la inconstitucionalidad y nulidad del art. 51 de la Ley Orgánica 2/2007, de 19

\section{Sentencia 32/2011, 71 de marzo (BOE de 11 de abril). Ponente: Aragón reyes (Recurso de inconstitucionalidad).}

Preceptos constitucionales: 147.2.d), 149.1.22, 149.3.

otros:

Objeto: Art. 75.1 del Estatuto de Autonomía de Castilla y León aprobado por la Ley Orgánica 14/2007, de 30 de noviembre, de reforma del Estatuto de Autonomía de Castilla y León.

Materias: Competencias estatales y autonómicas. Concepto de cuenca intercomunitaria; determinación de la competencia estatal de éstas.

Véase la STC 30/2011, en este mismo comentario, en la que ésta tiene su antecedente y reproduce formal y sustantivamente el aparato argumental para estimar el presente recurso de inconstitucionalidad y, en consecuencia declarar la inconstitucionalidad y nulidad del art. 75.1 del Estatuto de Autonomía de Castilla y León aprobado por la Ley Orgánica 14/2007, de 30 de noviembre, de reforma del Estatuto de Autonomía de Castilla y León. 